Marquette University

e-Publications@Marquette

6-24-2019

\title{
Selective Isomer Formation and Crystallization-Directed Magnetic Behavior in Nitrogen-Confused C-Scorpionate Complexes of $\mathrm{Fe}\left(\mathrm{O}_{3} \mathrm{SCF}_{3}\right)_{2}$
}

\author{
James R. Gardinier \\ Marquette University, james.gardinier@marquette.edu \\ Kristin J. Meise \\ Marquette University \\ Fathiya Jahan \\ Marquette University \\ Denan Wang \\ Marquette University \\ Sergey V. Lindeman \\ Marquette University, sergey.lindeman@marquette.edu
}

Follow this and additional works at: https://epublications.marquette.edu/chem_fac

Part of the Chemistry Commons

\section{Recommended Citation}

Gardinier, James R.; Meise, Kristin J.; Jahan, Fathiya; Wang, Denan; and Lindeman, Sergey V., "Selective Isomer Formation and Crystallization-Directed Magnetic Behavior in Nitrogen-Confused C-Scorpionate Complexes of $\mathrm{Fe}\left(\mathrm{O}_{3} \mathrm{SCF}_{3}\right)_{2}$ " (2019). Chemistry Faculty Research and Publications. 992.

https://epublications.marquette.edu/chem_fac/992 
Marquette University

\section{e-Publications@Marquette}

\section{Chemistry Faculty Research and Publications/College of Arts and Sciences}

This paper is NOT THE PUBLISHED VERSION; but the author's final, peer-reviewed manuscript. The published version may be accessed by following the link in the citation below.

Inorganic Chemistry, Vol. 58, No. 14 (June 24, 2019): 8953-8968. DOI. This article is (C American Chemical Society Publications and permission has been granted for this version to appear in $\underline{\mathrm{e}}-$ Publications@Marquette. American Chemical Society Publications does not grant permission for this article to be further copied/distributed or hosted elsewhere without the express permission from American Chemical Society Publications.

\section{Selective Isomer Formation and} Crystallization-Directed Magnetic Behavior in Nitrogen-Confused C-Scorpionate Complexes of $\mathrm{Fe}\left(\mathrm{O}_{3} \mathrm{SCF}_{3}\right)_{2}$

\section{James R. Gardinier}

Department of Chemistry, Marquette University, Milwaukee, Wisconsin

\section{Kristin J. Meise}

Department of Chemistry, Marquette University, Milwaukee, Wisconsin

\section{Fathiya Jahan}

Department of Chemistry, Marquette University, Milwaukee, Wisconsin

\section{Denan Wang}

Department of Chemistry, Marquette University, Milwaukee, Wisconsin

\section{Sergey V. Lindeman}

Department of Chemistry, Marquette University, Milwaukee, Wisconsin 


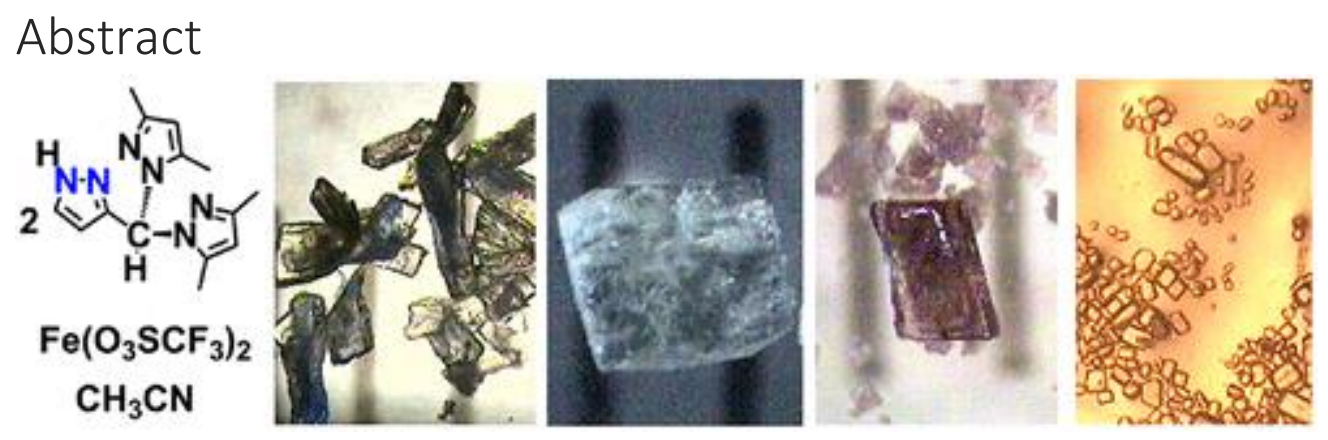

The complex $\left[\mathrm{Fe}\left({ }^{\mathrm{H}} \mathrm{L}^{*}\right)_{2}\right](\mathrm{OTf})_{2}, 1$, where ${ }^{\mathrm{H}} \mathrm{L}^{*}=$ bis(3,5-dimethylpyrazol-1-yl)(3-1H-pyrazole)methane, was prepared in order to compare its magnetic properties with those of the analogous parent complex, $\left[\mathrm{Fe}\left({ }^{\mathrm{H} L}\right)_{2}\right](\mathrm{OTf})_{2}$, that lacks methyl groups on pyrazolyl rings and that undergoes spin crossover (SCO) from the low spin (LS) to the high spin (HS) form above room temperature. It was anticipated that this new semibulky derivative should favor the HS state and undergo SCO at a lower temperature range. During this study, six crystalline forms of 1 were prepared by controlling the crystallization conditions. Thus, when reagents are combined in $\mathrm{CH}_{3} \mathrm{CN}$, an equilibrium mixture of cis and trans isomers is established that favors the latter below $311 \mathrm{~K}$. The trans isomer can be isolated exclusively as a mixture of solvates, $\mathrm{LS}$ trans $-1 \cdot 2 \mathrm{CH}_{3} \mathrm{CN}$ and $\mathrm{HS}$ trans $-1 \cdot 4 \mathrm{CH}_{3} \mathrm{CN}$, by cooling $\mathrm{CH}_{3} \mathrm{CN}$ solutions to $-20^{\circ} \mathrm{C}$ with the former being favored at high concentrations and short crystallization times. Subsequently, vapor diffusion of $\mathrm{Et}_{2} \mathrm{O}$ into $\mathrm{CH}_{3} \mathrm{CN}$ solutions of pure trans-1.2 $\mathrm{CH}_{3} \mathrm{CN}$ gives solvate-free HS trans-1. Subjecting trans $-\mathbf{1} \cdot 2 \mathrm{CH}_{3} \mathrm{CN}$ to vacuum at room temperature gives microcrystalline trans $-\mathbf{1} \cdot \mathrm{CH}_{3} \mathrm{CN}$, identified by elemental analysis and its distinct powder X-ray diffraction pattern. If an isomeric mixture of $\mathbf{1}$ is subject to room-temperature vapor diffusion, then a crystalline mixture of HS isomers cis-1 and trans-1 is obtained. Finally, slowly cooling hot acetonitrile solutions of isomeric mixtures of $\mathbf{1}$ to room temperature gives large prisms of $\mathrm{HS}$ co-1, a species with both cis and trans isomers in the unit cell. The complexes trans-1, trans-1. $\mathrm{CH}_{3} \mathrm{CN}, \mathrm{cis}-\mathbf{1}$, and co-1 undergo SCO below $250 \mathrm{~K}$ while trans-1. $x \mathrm{CH}_{3} \mathrm{CN}(x=2,4)$ solvates do not undergo SCO before desolvation.

\section{Synopsis}

The complex, $\left[\mathrm{Fe}\left({ }^{\mathrm{H}} \mathrm{L}^{*}\right)_{2}\right](\mathrm{OTf})_{2}, 1$, where ${ }^{\mathrm{H}} \mathrm{L}^{*}=$ bis(3,5-dimethylpyrazol-1-yl)(3-1H-pyrazole)methane, can be coerced to crystallize in one of four different forms from $\mathrm{CH}_{3} \mathrm{CN}$ solutions under normal laboratory conditions where each form has distinctive magnetic properties.

\section{Introduction}

Transition metal complexes that have metal centers with $\mathrm{d}^{4}$ to $\mathrm{d}^{7}$ electron configurations and ligands that impart intermediate fields to the metal can be provoked to undergo reversible spin crossover $(\operatorname{SCO})(1,2)$ between low spin (LS) and high spin (HS) electronic states via controlled perturbations to temperature, applied pressure, or various forms of electromagnetic radiation.(3-11) Since a given SCO complex in each of its electronic spin states exhibits different size, color, magnetic properties, and bulk solid-state electrical resistivity, there has been great interest in their potential employment for various technological applications.(12-20) The temperature dependence of bulk molar magnetic susceptibility $\left(\chi_{M}\right)$ is most often used to characterize SCO behavior since it is simple to measure and because $\chi_{M}$ directly correlates to the high spin fraction $\left(\gamma_{H S}\right)$ in the sample. The temperature with $\gamma_{\mathrm{HS}}=0.5$, or $T_{1 / 2}$, is generally used as a descriptive reference. The full $\chi_{\mathrm{M}}$ versus $T$ plots reveal whether or not the SCO is complete, if SCO occurs in one or more steps, and whether there is cooperativity in 
the form of either a large $\delta \chi_{\mathrm{M}} / \mathrm{d} T$ or a hysteresis (where $T_{1 / 2} \uparrow$ (heating) is different than $T_{1 / 2} \downarrow$ (cooling)), or both.(21) The requisite conditions ( $T, P, h v$, etc.) for the initiation and progression of SCO in the solid state depend not only on the metal ion and the ligand field strength, but also, critically, on the nature of the crystal packing. Thus, each polymorph(22) or solvatomorph(23) of a given complex typically exhibits magnetic behavior that is different than that of its relative. A longstanding research challenge in SCO compounds is to use molecular design and/or crystal engineering approaches to identify structure-property relationships with the goal of imparting a specific magnetic behavior $\left(T_{1 / 2}, \delta \chi_{\mathrm{M}} / \mathrm{d} T\right.$, number of SCO steps, etc.) into the bulk solid.

Within the profuse collection of transition metal complexes that exhibit SCO behavior, octahedral iron(II) complexes of organoamine and/or N-heterocyclic donors represent one of the largest and most intensely studied classes.(24-29) Of these, complexes of scorpionate ligands,(30,31) poly(pyrazolyl)borates or poly(pyrazolyl)methanes ( $\mathrm{C}$-scorpionates), have received increased scrutiny because of their interesting SCO behavior(32-39) and their attractive physical properties that are useful for materials processing.(40-47) While the SCO behavior of iron(II) scorpionates has shown some evidence of tunability via ligand modifications, (48-52) there is a need for elaboration in order to more fully understand the impact of substituent changes on fine-tuning ligand field strength and crystal packing, and, hence, controlling SCO behavior in this class of compounds.

We recently introduced a new class of C-scorpionate, the nitrogen-confused C-scorpionate, where the connectivity of one of the three heterocycles bound to the central methine carbon occurs at the 3-carbon ring position instead of the more usual $\mathrm{N}-1$ position. The iron(II) complexes $\left[\mathrm{Fe}\left({ }^{\mathrm{H}} \mathrm{L}\right)_{2}\right](\mathrm{X})_{2}\left(\mathrm{X}=\mathrm{BF}_{4},(53)\right.$ OTf(54)), where ${ }^{\mathrm{H}} \mathrm{L}$ is a ligand with two unsubstituted pyrazolyls and a "confused" pyrazolyl with an $\mathrm{N}-\mathrm{H}$ moiety, were studied. Both complexes are low spin (LS) at room temperature and undergo SCO with $T_{1 / 2}$ near $360 \mathrm{~K}$, but the triflate (OTf) derivative exhibited a more cooperative $\mathrm{SCO}$ than the $\mathrm{BF}_{4}$ derivative due to stronger intermolecular charge-assisted hydrogen-bonding interactions between the pyrazolyl- $\mathrm{NH}$ donor and anion acceptor (O versus F). It is known for iron(II) complexes of normal scorpionates that introducing methyl substituents at the 3pyrazolyl ring positions dramatically reduces $T_{1 / 2}$ of SCO presumably because interligand steric interactions of six methyl groups near the metal center favor the longer bond distances associated with the HS state. For instance, $\left\{\mathrm{Fe}\left[\mathrm{HC}\left(3,5-\mathrm{Me}_{2} \mathrm{pz}\right)_{3}=\mathrm{Tpm}^{*}\right]_{2}\right\}\left(\mathrm{BF}_{4}\right)_{2}$ has $T_{1 / 2}$ near $200 \mathrm{~K}(55)$ while $\left\{\mathrm{Fe}\left[\mathrm{HC}(\mathrm{pz})_{3}=\mathrm{Tpm}\right]\right\}\left(\mathrm{BF}_{4}\right)_{2}$ has $T_{1 / 2}$ near 400 K.(56) Lowering the number of methyls at the 3-pyrazolyl position gives $T_{1 / 2}$ between these two extremes as in the cases of $\left[\mathrm{Fe}\left\{\mathrm{HC}(3-\mathrm{Mepz})_{2}(5-\mathrm{Mepz})\right\}_{2}\right]\left(\mathrm{BF}_{4}\right)_{2}\left(T_{1 / 2}=250 \mathrm{~K}\right) \underline{(57)}$ or $[\mathrm{Fe}(\mathrm{Tpm} *)(\mathrm{Tpm})]\left(\mathrm{BF}_{4}\right)_{2}\left(T_{1 / 2}(\right.$ polymorph 1$) \sim$ $228 \mathrm{~K} ; T_{1 / 2}$ (polymorph 2) $310 \mathrm{~K}$ ). (58) Given these results and the current interest in discovering new examples of species that undergo thermal SCO with $T_{1 / 2}$ near room temperature,(59) we initiated a study of the SCO behavior of iron(II) complexes of $\mathrm{H}^{*}$, a $\mathrm{N}$-confused $\mathrm{C}$-scorpionate ligand with two 3,5-dimethylpyrazolyl rings and an unsubstituted "confused" pyrazolyl; such complexes would have four methyl groups near the metal center. During the course of these studies, we discovered that the iron(II) triflate complex showed unexpectedly rich structural chemistry that was responsible for the unusual thermal SCO behavior as evaluated by magnetometry measurements. This paper details the coordination chemistry, crystallization behavior, and resultant magnetic properties of $\left[\mathrm{Fe}\left({ }^{\mathrm{H}} \mathrm{L}^{*}\right)_{2}\right](\mathrm{OTf})_{2} \cdot x \mathrm{CH}_{3} \mathrm{CN}, 1 \cdot x \mathrm{CH}_{3} \mathrm{CN}$, where $x=0,1,2$, or 4 .

\section{Experimental Section}

\section{General Considerations}

Commercial solvents were dried by conventional means and distilled under a nitrogen atmosphere prior to use. Anhydrous $\mathrm{Fe}(\mathrm{OTf})_{2}$ was purchased from commercial sources and was purified by low temperature crystallization from $\mathrm{CH}_{3} \mathrm{CN} / \mathrm{Et}_{2} \mathrm{O}$ to give $\mathrm{Fe}(\mathrm{OTf}) \cdot 2 \mathrm{CH}_{3} \mathrm{CN}$ that was stored under argon in a drybox. (54) The compound ${ }^{H} L *$ was prepared as described elsewhere.(54) The iron(II) complex was prepared under argon using 
Schlenk line techniques; however, after isolation, it was stored and manipulated under normal laboratory atmospheric conditions.

\section{Instrumentation}

Midwest MicroLab, LLC, Indianapolis, IN, performed all elemental analyses. Melting point determinations were made on samples contained in glass capillaries using an Electrothermal 9100 apparatus and are uncorrected. IR spectra were recorded for samples as $\mathrm{KBr}$ pellets in the $4000-500 \mathrm{~cm}^{-1}$ region on a Nicolet Magna-IR 560 spectrometer or on solid samples using a Thermo Scientific Nicolet iS5 IR spectrometer equipped with an iD3 attenuated total reflection (ATR) accessory. ${ }^{1} \mathrm{H}$ NMR spectra were recorded on a Varian $400 \mathrm{MHz}$ spectrometer. Chemical shifts were referenced to the residual $\mathrm{CD}_{2} \mathrm{HCN}$ resonance $\underline{(60)}$ at $\delta_{\mathrm{H}} 1.94$ for $\mathrm{CD}_{3} \mathrm{CN}$. Solution magnetic moments were measured by the Evans method.(61) Magnetic susceptibility data were collected on a Quantum Design MPMS3 SQUID magnetometer. Raw moment data were corrected for sample shape and radial offset corrections using the MPMS 3 Sample Geometry Simulator.(62) Diamagnetic corrections of $-372 \times 10^{-6} \mathrm{emu} / \mathrm{mol}$ for each trans-1, cis-1, and co-1 calculated from tabulated Pascal's constants (63) were applied to the measured susceptibility data, as appropriate. Electronic absorption (UV-vis/NIR) measurements were made on a Cary 5000 instrument. Powder X-ray diffraction patterns were collected with an Oxford Diffraction Ltd. Supernova equipped with a 135 mm Atlas CCD detector or with a Rigaku Miniflex II instrument using Cu Ka radiation.

\section{Synthetic Protocol}

$\left[\mathrm{Fe}\left({ }^{\mathrm{H} L} \mathrm{~L}^{*}\right)_{2}\right](\mathrm{OTf})_{2}, 1$

A solution of $0.854 \mathrm{~g}(3.15 \mathrm{mmol})$ of ${ }^{\mathrm{H}} \mathrm{L}^{*}$ in $20 \mathrm{~mL}$ of $\mathrm{CH}_{3} \mathrm{CN}$ was added to a solution of $0.654 \mathrm{~g}(1.50 \mathrm{mmol})$ of $\mathrm{Fe}(\mathrm{OTf})_{2} \cdot 2 \mathrm{CH}_{3} \mathrm{CN}$ in $10 \mathrm{~mL}$ of $\mathrm{CH}_{3} \mathrm{CN}$. The flask originally containing ${ }^{\mathrm{H}} \mathrm{L}^{*}$ was washed with $5 \mathrm{~mL}$ of $\mathrm{CH}_{3} \mathrm{CN}$, and the washings were transferred to the reaction medium to ensure quantitative transfer of reagent. After the pale violet solution had been stirred $1 \mathrm{~h}$ at room temperature, solvent was removed under vacuum distillation with an external room-temperature water bath to facilitate evaporation. The pale lavender pink residue was washed with $\mathrm{Et}_{2} \mathrm{O}(3 \times 10 \mathrm{~mL})$ and was dried under vacuum to leave $1.073 \mathrm{~g}(80 \%)$ of 1 as a nearly colorless powder. $\mathrm{Mp}$, did not melt below $200{ }^{\circ} \mathrm{C}$. Anal. Calcd (Found) for 1, $\mathrm{C}_{30} \mathrm{H}_{36} \mathrm{~F}_{6} \mathrm{FeN}_{12} \mathrm{O}_{6} \mathrm{~S}_{2}$ : C, 40.28 (40.29); H, 4.06 (4.08); N, 18.79 (18.79). $\mu_{\text {eff }}\left(\right.$ Evans, $\left.\mathrm{CD}_{3} \mathrm{CN}\right)=4.9 \mu_{\mathrm{B}}$. IR: $\mathrm{v}_{\mathrm{NH}}(\mathrm{Nujol} / \mathrm{KBr})=3139 . \mathrm{IR}$ for triflate (Nujol/KBr, s to vs): 1286 ( $\left.\mathrm{V}_{\mathrm{as}}, \mathrm{SO}_{3}\right)$, $1256\left(v_{s}, C F_{3}\right), 1160\left(v_{a s}, C F_{3}\right), 1033\left(v_{s}, S_{3}\right), 638\left(\delta_{s}, S_{3}\right) \mathrm{cm}^{-1} . U V-v i s\left[C D_{3} C N\right] \lambda, n m\left(\varepsilon, M^{-1} \mathrm{~cm}^{-1}\right): 800(20), 467$ sh (90), 374 sh (280), 338 (600), 320 (640). See below for ${ }^{1} \mathrm{H}$ NMR data.

cis- $\left[\mathrm{Fe}\left({ }^{\mathrm{H}} \mathrm{L}^{*}\right)_{2}\right](\mathrm{OTf})_{2}$, cis-1

This isomer has not yet been obtained pure in a bulk form. The greatest amounts of this isomer as a powder admixed with small amounts of trans-1 are obtained by boiling a $\mathrm{CH}_{3} \mathrm{CN}$ solution of $\mathbf{1}$ to dryness with the aid of an external $90{ }^{\circ} \mathrm{C}$ oil bath (see Figure S6b for PXRD and Figure S11 for NMR). Single crystals of cis-1 could be selected (at random) from mixtures with trans-1 (see below) and analyzed by single crystal X-ray diffraction (scXRD), as follows. Room-temperature vapor diffusion of $\mathrm{Et}_{2} \mathrm{O}$ into a filtered $0.025 \mathrm{M} \mathrm{CH}_{3} \mathrm{CN}$ solution of 1 gave colorless plate-like needles which are a mixture of isomers, trans-1 and cis-1. One of the latter was handselected and used for SCXRD. The bulk colorless needle crystals were collected by decanting the mother liquor, washing with $\mathrm{Et}_{2} \mathrm{O}$, and drying under vacuum for $20 \mathrm{~min} .{ }^{1} \mathrm{H} \mathrm{NMR}\left(\mathrm{CD}_{3} \mathrm{CN}\right)$ analysis confirms the bulk crystals to be a mixture of isomers (see Figure $\mathrm{S} 10)$. The resonances attributed to the cis isomer are $\delta_{\mathrm{H}} 50.7(2 \mathrm{H}), 48.0(2$ H), $44.8(2 \mathrm{H}), 44.2(6 \mathrm{H}), 35.6(4 \mathrm{H}), 21.5(6 \mathrm{H}), 20.3(6 \mathrm{H}), 19.3(6 \mathrm{H}),-41.6(2 \mathrm{H}) \mathrm{ppm}$.

$\mathrm{CO}-\left[\mathrm{Fe}\left({ }^{\mathrm{H}} \mathrm{L}^{*}\right)_{2}\right](\mathrm{OTf})_{2}$, co-1

Crystallization by cooling a hot $\left(60^{\circ} \mathrm{C}\right) \mathrm{CH}_{3} \mathrm{CN}$ solution of $1\left(200 \mathrm{mg} / 1 \mathrm{~mL} \mathrm{CH}{ }_{3} \mathrm{CN}\right.$, ca. $\left.0.22 \mathrm{M}\right)$ to room temperature overnight gave $52 \mathrm{mg}$ of large, pale blue-green block-like prisms of co-1. An additional $47 \mathrm{mg}$ fraction was obtained by evaporating the mother liquor to $1 / 2$ the original volume by heating to $60^{\circ} \mathrm{C}$ under a nitrogen stream and then allowing the mother liquor to cool to room temperature for $2 \mathrm{~h}$. It then was cooled at 
$4{ }^{\circ} \mathrm{C}$ for $12 \mathrm{~h}$, followed by decanting and drying under nitrogen. A final $20 \mathrm{mg}$ crop of crystals was obtained by concentrating and cooling a second time as above. Anal. Calcd (Found) for co-1, $\mathrm{C}_{30} \mathrm{H}_{36} \mathrm{~F}_{6} \mathrm{FeN}_{12} \mathrm{O}_{6} \mathrm{~S}_{2}$ : $\mathrm{C}, 40.28$ (40.07); H, 4.06 (4.04); N, 18.79 (18.66). ${ }^{1} \mathrm{H}$ NMR ( $\left.\mathrm{CD}_{3} \mathrm{CN}\right) \delta_{H}$ 50.7, 50.5, 48.0, 44.7, 44.2, 37.5, 36.6, 35.6, 21.5, $20.4,19.6,19.3,2.22,-41.0,-41.7 \mathrm{ppm}$.

trans- $\left[\mathrm{Fe}\left({ }^{\mathrm{H} L}{ }^{*}\right)_{2}\left(\mathrm{CH}_{3} \mathrm{CN}\right) \mathrm{x}\right](\mathrm{OTf})_{2} \cdot x \mathrm{CH}_{3} \mathrm{CN}(\mathrm{x}=1,2$, or 4$)$, trans- $1 \times \mathrm{CH}_{3} \mathrm{CN}(\mathrm{x}=1,2$, or 4$)$ A solution of $500 \mathrm{mg}$ of $1 \mathrm{in} 7 \mathrm{~mL}$ of $\mathrm{CH}_{3} \mathrm{CN}$ was placed in a freezer at $-20^{\circ} \mathrm{C}$, and the solution became light violet on cooling. Large violet square plates of trans-1.2 $\mathrm{CH}_{3} \mathrm{CN}$ formed over $14 \mathrm{~h}$. The violet crystals of trans-1.2 $\mathrm{CH}_{3} \mathrm{CN}$ (251 mg) were separated from the mother liquor by decanting and drying under a $\mathrm{N}_{2}$ stream. Evaporating the mother liquor to about $1 / 3$ the volume and cooling another $14 \mathrm{~h}$ gave a second crop $(42 \mathrm{mg})$ of trans-1.2CH $\mathrm{CN}_{3}$. Total: $293 \mathrm{mg}$ of trans-1.2 $\mathrm{CH}_{3} \mathrm{CN}$. Note that if any trace colorless powder of trans-1.4CH $\mathrm{CH}_{3} \mathrm{CN}$ is present in the bulk crystallization, it can be removed by shaking and decanting the cold suspension from the larger violet crystals. Then, after drying under a nitrogen stream, the violet crystals of the disolvate are then separated mechanically from any opaque, pale aqua crystals of the (now desolvated) tetrasolvate. Longer crystallization times (4-7 days) or more dilute solutions produced a mixture of trans $-1 \cdot 2 \mathrm{CH}_{3} \mathrm{CN}$ and colorless prisms of trans-1.4CH${ }_{3} \mathrm{CN}$. If the crystallization time is extended to 2 weeks or more, then the violet crystals transform completely into colorless prisms of trans $-1 \cdot 4 \mathrm{CH}_{3} \mathrm{CN}$. The crystals of trans-1.4CH $\mathrm{CH}_{3} \mathrm{CN}$ rapidly desolvate under a $\mathrm{N}_{2}$ stream to give approximately $45 \mathrm{mg}$ of desolvated trans-1 per $100 \mathrm{mg}$ of 1 . The following ${ }^{1} \mathrm{H}$ NMR data are for violet trans1. $2 \mathrm{CH}_{3} \mathrm{CN} .{ }^{1} \mathrm{H}$ NMR $\left(\mathrm{CD}_{3} \mathrm{CN}, 295 \mathrm{~K}\right) \delta_{\mathrm{H}} 50.5(4 \mathrm{H}), 37.5(2 \mathrm{H}), 36.6(12 \mathrm{H}), 19.5(16 \mathrm{H}), 2.22(6 \mathrm{H}),-41.0(2 \mathrm{H}) \mathrm{ppm}$.

Samples of $1 \cdot 2 \mathrm{CH}_{3} \mathrm{CN}$ desolvate to $1 \cdot \mathrm{CH}_{3} \mathrm{CN}$ during shipping to the combustion analysis laboratory. Samples of $1 . \mathrm{CH}_{3} \mathrm{CN}$ can be prepared intentionally by subjecting $1 \cdot 2 \mathrm{CH}_{3} \mathrm{CN}$ to an oil pump vacuum (0.1 mTorr) at room temperature for $1 \mathrm{~h}$. Anal. Calcd (Found) for trans-1. $\mathrm{CH}_{3} \mathrm{CN}, \mathrm{C}_{32} \mathrm{H}_{39} \mathrm{~F}_{6} \mathrm{FeN}_{13} \mathrm{O}_{6} \mathrm{~S}_{2}$ : C, 41.07 (41.31); $\mathrm{H}, 4.20$ (4.29); N, 19.46 (19.70).

trans- $\left[\mathrm{Fe}\left({ }^{\mathrm{H}} \mathrm{L}^{*}\right)_{2}\right](\mathrm{OTf})_{2}$, trans-1

For method A, a $100 \mathrm{mg}(0.102 \mathrm{mmol})$ sample of trans $-1 \cdot 2 \mathrm{CH}_{3} \mathrm{CN}$ dissolved in $2 \mathrm{~mL}$ of $\mathrm{CH}_{3} \mathrm{CN}$ at room temperature (avoid heating) is immediately precipitated with $6 \mathrm{~mL}$ of $\mathrm{Et}_{2} \mathrm{O}$. The colorless powder, $81 \mathrm{mg}(0.091$ $\mathrm{mmol}, 89 \%)$, is collected after filtering and drying under a nitrogen stream. For method $\mathrm{B}$, a $65 \mathrm{mg}(0.067 \mathrm{mmol})$ sample of trans $-1 \cdot 2 \mathrm{CH}_{3} \mathrm{CN}$ is heated at $70{ }^{\circ} \mathrm{C}$ for $4 \mathrm{~h}$ under vacuum to give $46 \mathrm{mg}(0.051 \mathrm{mmol}, 76 \%)$ of trans-1 as a colorless powder. Anal. Calcd (Found) for trans-1, $\mathrm{C}_{30} \mathrm{H}_{36} \mathrm{~F}_{6} \mathrm{FeN}_{12} \mathrm{O}_{6} \mathrm{~S}_{2}: \mathrm{C}, 40.28$ (40.34); H, 4.06 (4.04); N, 18.79 (18.70).

\section{X-ray Crystallography}

$\mathrm{X}$-ray intensity data from a violet prism of cis-1, a violet needle of trans-1, a violet irregular crystal of co-1, a violet prism of trans $-1 \cdot 2 \mathrm{CH}_{3} \mathrm{CN}$, and a colorless prism of trans-1.4 $\mathrm{CH}_{3} \mathrm{CN}$ were collected at $100.0(1) \mathrm{K}$ with an Oxford Diffraction Ltd. Supernova equipped with a $135 \mathrm{~mm}$ Atlas CCD detector. The data for trans-1, cis-1, and co-1 were also collected at $250 \mathrm{~K}$ (a temperature where the latter two crystals were colorless but the former was light violet/pink). Cu K $\alpha$ radiation, $\lambda=1.54184 \AA$, was used for all experiments except for trans-1 which used Mo K $\alpha$ radiation, $\lambda=0.71073 \AA$. Raw data frame integration and $L p$ corrections were performed with CrysAlis Pro (Oxford Diffraction, Ltd.).(64) Final unit cell parameters were determined by least-squares refinement of 18495 (100 K) and 14400 (250 K) reflections from the data set of cis-1, 22417 (100 K) and 17127 (250 K) reflections from the data set of co-1, 10392 (100 K) reflections from the data set of trans-1·2CH $\mathrm{CN}_{1} 13813$ (100 $\mathrm{K})$ reflections from the data set of trans $-1 \cdot 4 \mathrm{CH}_{3} \mathrm{CN}$, and $15651(100 \mathrm{~K})$ and $10071(250 \mathrm{~K})$ reflections from the data set of trans-1, with $I>2 \sigma(I)$ for all cases. Analysis of the data showed negligible crystal decay during collection in each case. Direct methods structure solutions were performed with Olex2.solve (65) while difference Fourier calculations and full-matrix least-squares refinements against $F^{2}$ were performed with SHELXTL.(66) Empirical absorption corrections were applied using spherical harmonics implemented in the 
SCALE3 ABSPACK scaling algorithm. The hydrogen atom bound to nitrogen of the pyrazol-3-yl group in cis1, trans-1 $(100 \mathrm{~K})$, and trans-1.2 $\mathrm{CH}_{3} \mathrm{CN}$ was located and refined. All other hydrogen atoms were placed in idealized positions and included as riding atoms.

Special details follow. For cis-1, one of the triflate anions is well-ordered while the other is unequally disordered, 67\%:33\%, over two nearby positions. At high temperature the extreme disorder causes an A-level alert in the checkcif program; this alert is resolved in the $100 \mathrm{~K}$ structure. Also, a modulated phase with q-vector (0.077 0 0.171) was found at $100 \mathrm{~K}$; no satellites were detected at $250 \mathrm{~K}$. For co-1, one of the triflate ions is disordered over two nearby positions. The major component (84\%) is hydrogen-bonded to the pyrazolyl. The minor component occupies an alternative position in a cavity. The content of the cavity could not be elucidated but may involve a small amount of unidentified solvent and/or a third orientation of the anion. The crystal of trans-1 at $100 \mathrm{~K}$ was a twin where component two is rotated $180^{\circ}$ around [ $-0.01-0.021 .00$ ] (reciprocal space) or [0.00 0.001 .00 ] (direct space). The crystal of trans-1.2 $\mathrm{CH}_{3} \mathrm{CN}$ was an $87 / 8 / 5$ triplet where component 2 was rotated by $-170.9^{\circ}$ around [-0.05 $1.00-0.01$ ] (reciprocal space) or [-0.05 1.00 -0.02] (direct space) while component 3 was rotated by $-174.6^{\circ}$ around [ $\left.-0.021 .000 .00\right]$ (reciprocal space) or [-0.01 1.00 -0.00] (direct space).

\section{Computational Details}

\section{General Considerations}

Geometry optimizations were performed using Handy's optimized exchange (OPTX) with the PBE correlation (OPBE functional)(67) in combination with the def2-SV(P) double- $\zeta$ basis set for light atoms and def2-QZVPP for $\mathrm{Fe}(68)$ because we have previously found(69) (and find again here) that this method provides excellent agreement (within $0.09 \AA$ ) with solid-state structures. Moreover, such an approach has been found to successfully determine spin-state splitting in other iron complexes that undergo spin crossover phenomena.(70) Solvent effects were accounted for by using the polarizable continuum model IEFPCM,(71) as implemented in Gaussian 16.(72) Analytical vibrational frequency calculations were carried out to verify that optimized geometries were stationary points. Table S7 summarizes the results of these studies. Cartesian coordinates are contained within the FeConf_DFT.xyz file found in the Supporting Information.

\section{Results and Discussion}

The reaction between Fe(OTf $)_{2}$ and 2 equiv of ${ }^{\mathrm{H}} \mathrm{L}^{*}$ in $\mathrm{CH}_{3} \mathrm{CN}$ gives the desired complex $\left[\mathrm{Fe}\left({ }^{\mathrm{H}} \mathrm{L}^{*}\right)_{2}\right](\mathrm{OTf})_{2}, \mathbf{1}$, in high yield. Recrystallization of 1 under different conditions led to the different crystal types pictured in Figure 1. Recrystallization of 1 by room-temperature vapor diffusion of $\mathrm{Et}_{2} \mathrm{O}$ into $\mathrm{CH}_{3} \mathrm{CN}$ solutions produced plate-like needles that are a mixture of cis and trans isomers, as defined by the relative disposition of the confused pyrazolyl ring on each ligand about iron's coordination sphere. The unit cell parameters of the crystals of each isomer at $250 \mathrm{~K}$ are nearly identical, so it is very difficult to distinguish these crystals by visual inspection. The trans isomer can be isolated by alternate means (vide infra). This mixture of needles was sometimes accompanied by large isometric crystalline blocks (left of Figure 1) that were found to contain both cisand trans-[Fe $\left.\left({ }^{\mathrm{H}} \mathrm{L}^{*}\right)_{2}\right]^{2+}$ cations in the same unit cell, so this crystal form is referred to as co-1. Crystals of co-1 are also formed predominantly in a mixture along with smaller amounts of plate-like needle mixtures of trans$\mathbf{1}$ and cis-1 by slow evaporation of $\mathrm{CH}_{3} \mathrm{CN}$ solutions of $\mathbf{1}$. Crystals of co-1 are best isolated (giving the highest quality crystals without contamination of needles) by slowly cooling hot concentrated (ca. $>0.2 \mathrm{M}) \mathrm{CH}_{3} \mathrm{CN}$ solutions to room temperature or to $4{ }^{\circ} \mathrm{C}$ (at the sacrifice of crystal quality). Recrystallization of lower concentrations of 1 in $\mathrm{CH}_{3} \mathrm{CN}$ ( $\leq \mathrm{ca} .0 .10 \mathrm{M}$ ) at low temperature $\left(-20^{\circ} \mathrm{C}\right)$ gave different $\mathrm{CH}_{3} \mathrm{CN}$ solvates of trans-1. More specifically, when dilute solutions are placed directly in a $-20^{\circ} \mathrm{C}$ freezer, violet crystals of a hydrogenbonded bis-acetonitrile solvate trans- $\left[\mathrm{Fe}\left({ }^{\mathrm{H}} \mathrm{L}^{*}\right)_{2}\right](\mathrm{OTf})_{2} \cdot 2 \mathrm{CH}_{3} \mathrm{CN}$, trans-1.2 $\mathrm{CH}_{3} \mathrm{CN}$, form (Figure 1, center) after about 1 day, followed by colorless block-like prisms of the tetrasolvate, trans-1.4CH ${ }_{3} \mathrm{CN}$ (Figure 1 , right). If 
crystallization chambers are left for extended periods ( 2 weeks to 1 month), the initially formed violet crystals eventually transform to colorless trans-1.4CH $\mathrm{CH}_{3} \mathrm{CN}$. Alternatively, when more dilute $(<0.02 \mathrm{M})$ solutions are cooled in a $-20^{\circ} \mathrm{C}$ freezer, the resulting crystal mixture is composed mainly of trans $-1 \cdot 4 \mathrm{CH}_{3} \mathrm{CN}$ with minor amounts of the disolvate. If crystals of trans-1·x $\mathrm{CH}_{3} \mathrm{CN}(x=2,4)$ are subject to recrystallization by vapor diffusion of $\mathrm{Et}_{2} \mathrm{O}$ into $\mathrm{CH}_{3} \mathrm{CN}$ solutions at $4{ }^{\circ} \mathrm{C}$, then a mixture of trans-1 and trans-1.2 $\mathrm{CH}_{3} \mathrm{CN}$ is obtained.
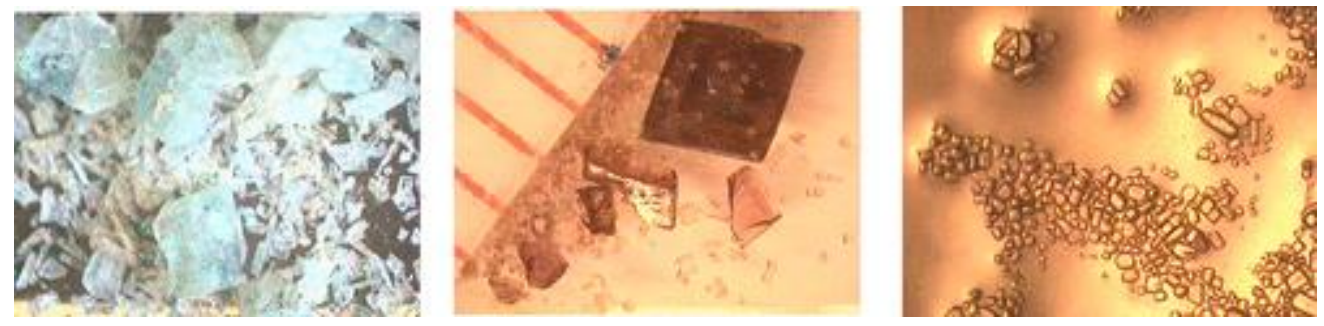

Figure 1. Left: Photograph of the mixture of crystals obtained after recrystallizing 1 by vapor diffusion of $\mathrm{Et}_{2} \mathrm{O}$ into a $0.025 \mathrm{M} \mathrm{CH}_{3} \mathrm{CN}$ solution, filtering, and drying under vacuum, producing a mixture of large blocks of co1 and smaller plate-like needles of cis-1 and trans-1. Center: Photograph of crystals of trans-1.2 $\mathrm{CH}_{3} \mathrm{CN}$ obtained after cooling a $\mathrm{CH}_{3} \mathrm{CN}$ solution of 1 to $-20^{\circ} \mathrm{C}$, after decanting the mother liquor, and (immediately) after drying under a nitrogen stream. Right: Crystals of trans-1.4C $\mathrm{CH}_{3} \mathrm{CN}$ in their mother liquor. Each photograph was taken under the same magnification.

\section{Solid-State Structures}

Crystals of trans-1 $x \mathrm{CH}_{3} \mathrm{CN}(x=2$ or 4 ) maintained their color over the temperature range $298-100 \mathrm{~K}$ while trans1, cis-1, and co-1 changed from colorless at room temperature to violet at $100 \mathrm{~K}$. Thus, the crystal structures of the former two complexes were determined at $100 \mathrm{~K}$ while those of the latter complexes were determined at two temperatures $\left(250 \mathrm{~K}\right.$ (colorless) and $100 \mathrm{~K}$ (violet)). The structures of the trans-1 $x \mathrm{CH}_{3} \mathrm{CN}$ solvates $(x=2$ or 4$)$ will be described briefly first, and then the structures of the other compounds are described in more detail because unusual features of their crystal packing dictate their peculiar magnetic behavior.

Views of the structure of trans-1.2 $\mathrm{CH}_{3} \mathrm{CN}$ are shown in Figure 2 while selected bond distances and angles are listed in Table1. The asymmetric unit consists of an iron(II) ion located on an inversion center, one $\mathrm{K}^{3} \mathrm{~N}$-ligand, one triflate anion, and one $\mathrm{CH}_{3} \mathrm{CN}$ molecule. The crystal symmetry gives a pseudo-octahedral FeN $\mathrm{N}_{6}$ kernel with an average Fe-N bond length of 1.97(3) $\AA$. This distance is characteristic of low spin (LS) iron(II) and is identical to that previously found in $\left[\mathrm{Fe}\left({ }^{\mathrm{H}} \mathrm{L}\right)_{2}\right]\left(\mathrm{BF}_{4}\right)_{2}$ that possessed a dication with unsubstituted "normal" pyrazolyls and that was shown to be $100 \%$ LS iron(II) by magnetometry.(53) In the dication of trans $-1 \cdot 2 \mathrm{CH}_{3} \mathrm{CN}$, the Fe-N distance associated with the "confused" pyrazolyl is much shorter (Fe-N2 1.936(2) $\AA$ ) than those of the other two pyrazolyls (Fe-N11, 1.991(2) $\AA$; Fe-N21 1.997(2) $\AA$ ). The ligand is relatively strain-free with no discernible distortions (52) which normally manifest in pyrazolyl ring twisting (pz twist = average of the absolute value of the two torsion angles, $\left|\mathrm{FeN}-\mathrm{NC}_{\text {methine }}\right|$, and the corresponding confused pyrazolyl's torsion $\left|\mathrm{FeN}-\mathrm{CC}_{\text {methine }}\right| \geq 0^{\circ}$ (untwisted value); here, $\mathrm{pz}$ twist $=1.4^{\circ}$ ) and pyrazolyl ring tilting ( $\mathrm{pz}$ tilt $=$ average of the two $\left|\mathrm{FeN}-\mathrm{NC} \mathrm{c}_{\mathrm{pz}}\right|$ torsions and "confused" $p z$ ring equivalent $\left|\mathrm{FeN}-\mathrm{C}_{\mathrm{pz}} \mathrm{C}_{\mathrm{pz}}\right|$ torsion $\leq 180^{\circ}$ (untilted value); here, the pz tilt = $\left.177.8^{\circ}\right)$. Finally, the "confused" pyrazolyl N-H was located and refined (N1-H1n 0.86(3) $\AA$ ) and is, somewhat

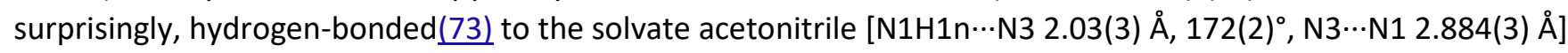
rather than to the triflate anions. The triflate anions are instead associated with acidic methine and pyrazolyl ring hydrogens $(\mathbf{7 4})$ and with solvate methyl hydrogens on neighboring dications to give the three-dimensional supramolecular structure, as detailed more fully in the Supporting Information. 

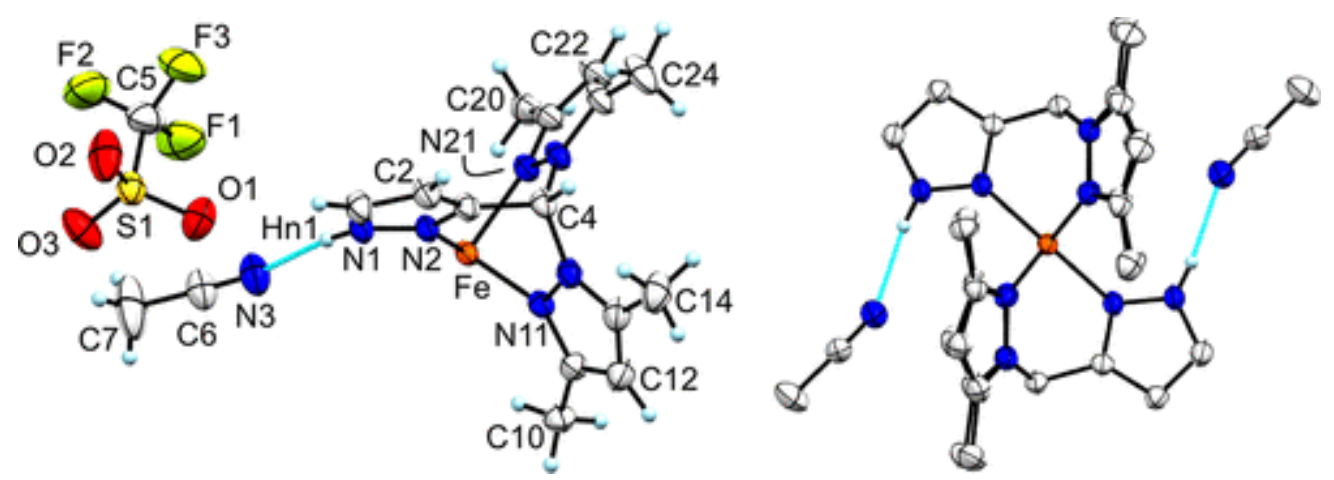

Figure 2. Left: Asymmetric unit of trans-1.2 $\mathrm{CH}_{3} \mathrm{CN}$, minor disorder component of anion and solvate atoms omitted for clarity. Thermal ellipsoids are shown at $50 \%$ probability. Right: View of the dication showing transdisposition of the "confused" pyrazolyls, with most hydrogen atoms omitted for clarity.

Table 1. Selected Bond Distances ( $\AA$ ), Angles (deg), and Torsions (deg) for trans-1· $x \mathrm{CH}_{3} \mathrm{CN}(x=2,4)$

\begin{tabular}{|l|l|l|}
\hline & $1 \cdot 2 \mathrm{CH}_{3} \mathrm{CN}$ & $1 \cdot 4 \mathrm{CH}_{3} \mathrm{CN}$ \\
\hline Bond Distances (A) & & \\
\hline Fe-N2 & $1.9364(17)$ & $2.1297(10)$ \\
\hline Fe-N11 & $1.9908(18)$ & $2.1799(11)$ \\
\hline Fe-N21 & $1.9964(16)$ & $2.2147(11)$ \\
\hline N1-H1n & $0.86(3)$ & 0.88 \\
\hline Bond Angles (deg) & & \\
\hline N2-Fe-N11 & $87.93(6)$ & $83.85(4)$ \\
\hline N2-Fe-N21 & $87.71(6)$ & $83.61(4)$ \\
\hline N11-Fe-N21 & $86.95(7)$ & $83.28(4)$ \\
\hline N2-Fe1-N2' & $180.00(8)$ & $180.00(6)$ \\
\hline N2-Fe-N11' & $92.07(6)$ & $96.15(4)$ \\
\hline N11-Fe-N21' & $93.05(7)$ & $96.72(4)$ \\
\hline Bond Torsions (deg) & & \\
\hline FeN2-C3C4 & $-0.3(2)$ & $10.15(15)$ \\
\hline FeN11-N12C4 & $-1.7(2)$ & $7.89(14)$ \\
\hline FeN21-N22C4 & $-2.0(2)$ & $12.92(14)$ \\
\hline FeN2-C3C2 & $-179.47(13)$ & $-171.42(8)$ \\
\hline FeN11-N12C13 & $177.51(13)$ & $-173.03(8)$ \\
\hline FeN21-N22C23 & $176.40(13)$ & $-161.71(8)$ \\
\hline
\end{tabular}

The structure of trans $-1 \cdot 4 \mathrm{CH}_{3} \mathrm{CN}$ at $100 \mathrm{~K}$ contrasts that of the disolvate in that the dication in the tetrasolvate is HS iron(II) as opposed to LS iron(II) found in the disolvate, a difference that can be attributed to the crystal packing, as described below. A comparison of bond distances and angles between the tetra- and disolvates is found in Table1. Thus, the average Fe-N distance of $2.17 \AA$ in the tetrasolvate is characteristic for HS iron(II) versus $1.97 \AA$ for LS iron(II) in the disolvate. Moreover, the ligand in the tetrasolvate is significantly distorted (Figure 3 , left) but is not very distorted in the disolvate. That is, the tetrasolvate has both greater pyrazolyl ring twisting $\left(10.3^{\circ}\right.$ vs $\left.1.4^{\circ}\right)$ and pyrazolyl ring tilting $\left(168.7^{\circ}\right.$ vs $\left.177.8^{\circ}\right)$ than the disolvate. In fact, the large pz twist in the tetrasolvate is close to the previously identified empirical $11^{\circ} \mathrm{pz}$ twist limit(52) whereby spin crossover has never been observed for an iron(II) scorpionate. This empirical limit presumably reflects that any large distortion(s) caused by crystal packing imparts an insurmountable kinetic barrier (especially at low temperature) for reorganization to a hypothetical undistorted low spin form. In trans-1.4 $\mathrm{CH}_{3} \mathrm{CN}$, two of the acetonitriles are

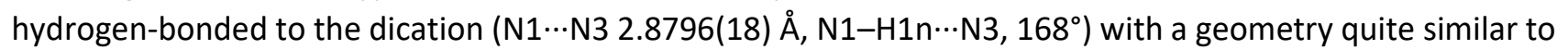


that in trans-1.2 $2 \mathrm{CH}_{3} \mathrm{CN}$, vide supra (center of Figure 3). However, the other two acetonitrile molecules of solvation in $1.4 \mathrm{CH}_{3} \mathrm{CN}$ are loosely held in pockets along the $c$-axis (Figure 3 , right) by $\mathrm{CH} \cdots \mathrm{O}(74)$ weak hydrogen-

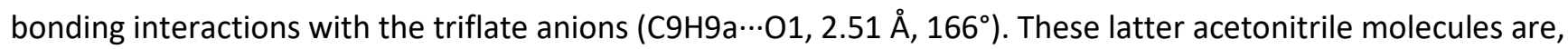
in turn, pressed against the most distorted $\mathrm{pz} *$ ring (with $\mathrm{N} 21$ ) to give a short $\mathrm{CH} \cdots \pi$ interaction(75) between the acetonitrile methyl donor and pyrazolyl acceptor (CH9b … Ct(N21) $2.73 \AA$, $132^{\circ}$ ).
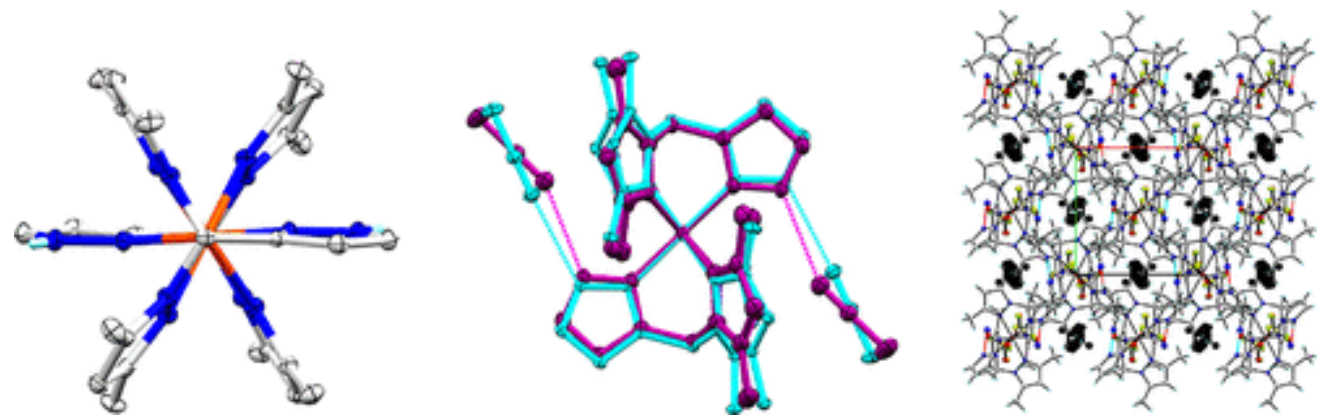

Figure 3. Left: View of the dication of trans-1.4CH $\mathrm{CH}_{3} \mathrm{CN}$ down the $\mathrm{C}_{\text {methine }}-\mathrm{Fe}$ vector with most $\mathrm{H}$ atoms and all $\mathrm{CH}_{3} \mathrm{CN}$ and triflate atoms removed for clarity to emphasize pyrazolyl ring twisting. Center: Comparison of dications in trans-1.4 $4 \mathrm{CH}_{3} \mathrm{CN}$ (cyan) versus in trans-1.2 $\mathrm{CH}_{3} \mathrm{CN}$ (violet). Right: View of crystal packing of trans$1.4 \mathrm{CH}_{3} \mathrm{CN}$ showing half of the acetonitrile molecules (as larger black ball and sticks) in channels/pockets along the $c$-axis.

Single crystal X-ray diffraction data was obtained for a colorless needle of cis-1 at $250 \mathrm{~K}$ and then after cooling to $100 \mathrm{~K}$ when the needle was violet (Figure 4). A listing of selected bond distances and interatomic angles for cis1 at different temperatures is provided in Table2. The compound crystallizes in the space group $P 2_{1} / c$ where the asymmetric unit is composed of one cation, one well-ordered triflate anion, and another triflate anion that is disordered unequally (2:1) over two nearby positions. The $\mathrm{FeN}_{6}$ coordination environment is distorted octahedral since the Fe-N bonds of the confused pyrazolyl are at least $0.02 \AA$ shorter than those of the (inequivalent) pz* groups. At $250 \mathrm{~K}$, the average Fe-N bond distance of the six bonds is $2.17(2) \AA$ which is aligned with expectations for HS iron(II). At $100 \mathrm{~K}$, the average distance shortens to $2.11(2) \AA$, indicative of an increasing portion (ca. 33\%) of LS iron(II). For reference, the compound $\left[\mathrm{Fe}\left({ }^{\mathrm{Bn}} \mathrm{L}\right)_{2}\right]\left(\mathrm{BF}_{4}\right)_{2} \cdot 2 \mathrm{CH}_{3} \mathrm{CN}$ (with an N-benzyl on the "confused" pyrazolyl and unsubstituted "normal" pyrazolyls) had an average Fe-N bond distance of 2.14 $\AA$ at $250 \mathrm{~K}$ (partly LS) and $1.99 \AA$ at $100 \mathrm{~K}$ (fully LS).(53) In cis-1, the average pyrazolyl ring twist is $6^{\circ}$ at both temperatures; thus, spin crossover behavior is expected and is observed in this case, vide infra.
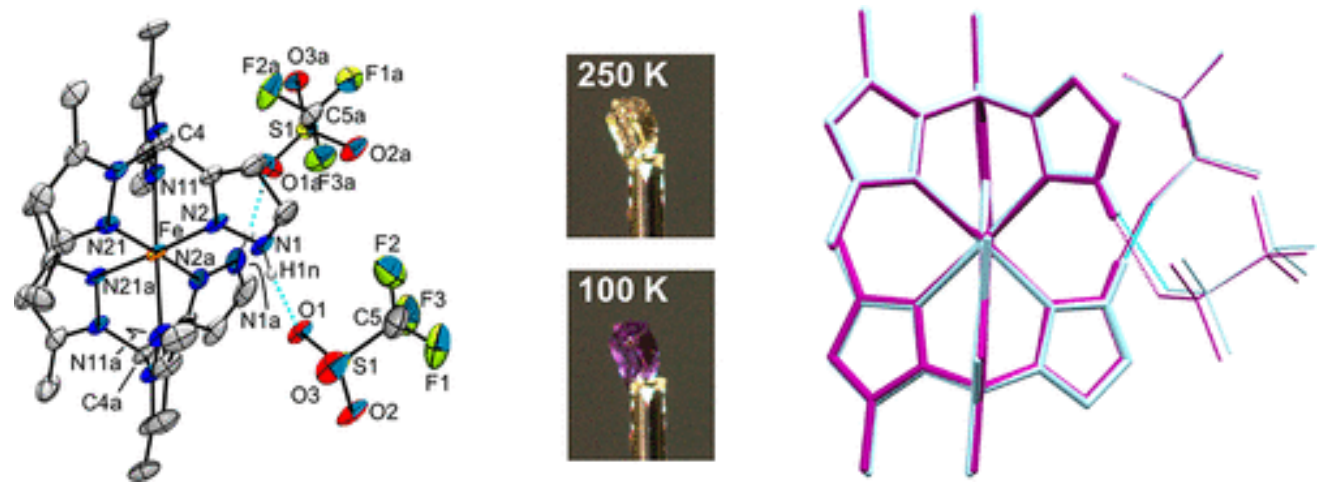

Figure 4. Left: Structure of cis-[Fe $\left.\left({ }^{\mathrm{H}} \mathrm{L}^{*}\right)_{2}\right](\mathrm{OTf})_{2}$, cis-1, at $100 \mathrm{~K}$. Middle: Photographs of a crystal at different temperature. Right: Overlay of structures obtained at $250 \mathrm{~K}$ (light blue) and $100 \mathrm{~K}$ (violet).

Table 2. Bond Distances ( $\AA$ ), Angles (deg), and Torsion Angles (deg) for cis-1

\begin{tabular}{|l|l|l|}
\hline & $250 \mathrm{~K}$ & $100 \mathrm{~K}$ \\
\hline Bond Distances (̊̊) & & \\
\hline
\end{tabular}




\begin{tabular}{|l|l|l|}
\hline Fe1-N2 & $2.146(2)$ & $2.0849(17)$ \\
\hline Fe1-N11 & $2.173(2)$ & $2.1089(14)$ \\
\hline Fe1-N21 & $2.192(2)$ & $2.1356(15)$ \\
\hline Fe1-N2a & $2.146(2)$ & $2.0833(16)$ \\
\hline Fe1-N11a & $2.196(2)$ & $2.1404(16)$ \\
\hline Fe1-N21a & $2.177(2)$ & $2.1242(17)$ \\
\hline Bond Angles (deg) & & \\
\hline N2-Fe1-N11 & $82.57(9)$ & $83.46(6)$ \\
\hline N2-Fe1-N21 & $83.77(9)$ & $84.47(6)$ \\
\hline N11-Fe1-N21 & $85.25(9)$ & $86.14(5)$ \\
\hline N2a-Fe1-N11a & $82.36(9)$ & $83.52(6)$ \\
\hline N2a-Fe1-N21a & $83.75(9)$ & $84.29(6)$ \\
\hline N11a-Fe1-N21a & $85.52(9)$ & $86.59(6)$ \\
\hline Bond Torsions (deg) & & \\
\hline C4C3-N2Fe1 & $-9.3(3)$ & $-8.3(2)$ \\
\hline C4N12-N11Fe1 & $2.3(3)$ & $1.7(2)$ \\
\hline C4N22-N21Fe1 & $-9.7(3)$ & $-9.1(2)$ \\
\hline C4aC3a-N2aFe1 & $-2.7(3)$ & $-3.9(2)$ \\
\hline C4aN12a-N11aFe1 & $5.5(3)$ & $3.2(2)$ \\
\hline C4aN22a-N21aFe1 & $-8.3(3)$ & $-10.8(2)$ \\
\hline
\end{tabular}

The three-dimensional supramolecular structure of cis-1 is constructed from $\mathrm{N}-\mathrm{H} \cdots \mathrm{O},(73) \mathrm{C}-\mathrm{H} \cdots \mathrm{O},(74)$ and $\mathrm{C}-$ $\mathrm{H} \cdots \mathrm{F}(76)$ weak charge-assisted hydrogen-bonding interactions involving hydrogen donors of the dications and either oxygen or fluorine acceptors of the triflate anions (Table3 and Figure 5 ). One of the triflate anions is disordered in a 2:1 ratio over two positions; thus, the discussion will first focus on the well-ordered triflate anion with atoms $\mathrm{O} 1, \mathrm{O} 2$, and $\mathrm{O} 3$. A sheet of cations is formed in the ac-plane by the $\mathrm{N}-\mathrm{H} \cdots \mathrm{O}$ and $\mathrm{C}-\mathrm{H} \cdots \mathrm{O}$ weak hydrogen-bonding interactions involving these well-ordered triflate anions (contact nos. 1 and $4-8$ in $\underline{\text { Table } 3}$ ). That is, a dimer is formed by a pair of triflate anions bridging two dications where $\mathrm{O} 1$ of the triflate interacts

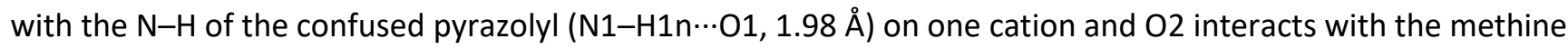
hydrogen, $\mathrm{H} 4 \mathrm{a}$, of the neighboring dication. This hydrogen-bonding interaction is in the range found for other hydrogen-bonded iron(II) SCO compounds: for instance, $\mathrm{N}-\mathrm{H} \cdots \mathrm{O}$ interactions in [Fe(2,6-bis(pyrazol-3yl)pyridine $)_{2}$ ( (cis, cis-1,3,5-cyclohexanetricarboxylate dianion) $\cdot 5.5 \mathrm{H}_{2} \mathrm{O}$ ranging from 1.73 to $1.86 \AA$, $(77)$ those in [Fe(2,6-bis[5-methyl-1H-pyrazol-3-yl]pyridine) $\left.{ }_{2}\right]\left(\mathrm{ClO}_{4}\right)_{2}$-solvate (solvate $=\mathrm{H}_{2} \mathrm{O}, \mathrm{MeOH}$, or $\mathrm{MeNO}_{2}$ ) ranging from 1.80 to $2.26 \AA$, (78) or those in [Fe(2-(pyrazol-1-yl)-6-(pyrazol-3-yl)pyridine $\left.)_{2}\right]\left(\mathrm{ClO}_{4}\right)_{2}$ of 1.93 and $2.03 \AA$. (79) The dimers are organized into sheets parallel with the ac-plane (containing the two dications in the middle of the unit cell in Figure 5 b) by interactions of $\mathrm{O} 2$ and $\mathrm{O} 3$ of one dimer with the hydrogens at the 4-positions of the dimethylpyrazolyl groups of neighboring dimers (interactions 7 and 8, Table3). The ac-sheets are stacked along the $b$-axis by hydrogen-bonding interactions with oxygen atoms of the disordered triflate (major disorder component, contact nos. 2, 9, 11, and 13; minor disorder component, contact nos. 3, 10, and 12 in Table3). Importantly, each contact with the disordered triflate falls well below the limits for $\mathrm{NH} \cdots \mathrm{O}$ or $\mathrm{CH} \cdots \mathrm{O}$ interactions and is in the range of that for medium-strength hydrogen bonds.(67) Similarly, the acidic methine hydrogen, $\mathrm{H} 4$, of one ac-sheet acts as a donor to triflate oxygens from an adjacent sheet (67\% involve contact 9 , and $33 \%$ involve contact $10, \underline{\text { Table3 }})$ where both associated $\mathrm{C} \cdots \mathrm{O}$ distances are well within the accepted limits for a $\mathrm{CH} \cdots \mathrm{O}$ interaction.(68) The minor component of the disordered triflate also has a number of $\mathrm{CH} \cdots \mathrm{F}$ weak hydrogenbonding interactions that serve to support the structure but will not be discussed further. The overall supramolecular structure is retained at $250 \mathrm{~K}$, but all contacts are elongated versus those at $100 \mathrm{~K}$. 
Table 3. Geometries of Main $\mathrm{N}-\mathrm{H} \cdots \mathrm{O}$ and $\mathrm{C}-\mathrm{H} \cdots \mathrm{O}$ Weak Hydrogen-Bonding Interactions in cis-1 at $100 \mathrm{~K}$

\begin{tabular}{|c|c|c|c|c|c|}
\hline contact & donor $(D)(-H) \cdots$ acceptor $(A)$ & $\mathrm{D}-\mathrm{H}(\AA)$ & $\mathrm{H} \cdots \mathrm{A}(\AA)$ & $D \cdots A(\AA)$ & D-H $\cdots A$ (deg) \\
\hline 1 & $\mathrm{~N} 1-\mathrm{H} 1 \mathrm{n} \cdots \mathrm{O} 1$ & $0.83(3)$ & $1.98(3)$ & $2.795(2)$ & 170(3) \\
\hline 2 & N1a-H1na...01a & $0.83(3)$ & $1.96(3)$ & $2.678(3)$ & $143(2)$ \\
\hline 3 & N1a-H1na...01b & $0.83(3)$ & $2.29(3)$ & $3.103(5)$ & 165(3) \\
\hline 4 & $\mathrm{C} 2 \mathrm{a}-\mathrm{H} 2 \mathrm{a} \cdots \mathrm{O} 2$ & 0.95 & 2.55 & $3.243(3)$ & 130 \\
\hline 5 & $\mathrm{C} 4 \mathrm{a}-\mathrm{H} 4 \mathrm{a} \cdots \mathrm{O} 2$ & 1.00 & 2.26 & $3.188(2)$ & 154 \\
\hline 6 & $\mathrm{C} 24 \mathrm{a}-\mathrm{H} 24 \mathrm{a} \cdots \mathrm{O} 2$ & 0.98 & 2.48 & $3.401(3)$ & 156 \\
\hline 7 & $\mathrm{C} 12-\mathrm{H} 12 \cdots 02$ & 0.95 & 2.56 & $3.445(2)$ & 156 \\
\hline 8 & $\mathrm{C} 22-\mathrm{H} 22 \cdots 03$ & 0.95 & 2.48 & $3.190(2)$ & 132 \\
\hline 9 & $\mathrm{C} 4-\mathrm{H} 4 \cdots 02 \mathrm{a}$ & 1.00 & 2.23 & $3.157(14)$ & 154 \\
\hline 10 & $\mathrm{C} 4-\mathrm{H} 4 \cdots 02 \mathrm{~b}$ & 1.00 & 2.42 & $3.34(3)$ & 153 \\
\hline 11 & $\mathrm{C} 2-\mathrm{H} 2 \cdots 02 \mathrm{a}$ & 0.95 & 2.54 & $3.22(2)$ & 128 \\
\hline 12 & $\mathrm{C} 2-\mathrm{H} 2 \cdots 02 \mathrm{~b}$ & 0.95 & 2.57 & $3.29(3)$ & 133 \\
\hline 13 & $\mathrm{C} 20 \mathrm{a}-\mathrm{H} 20 \mathrm{~b} \cdots 03 \mathrm{O}$ & 0.98 & 2.44 & $3.420(5)$ & 176 \\
\hline
\end{tabular}

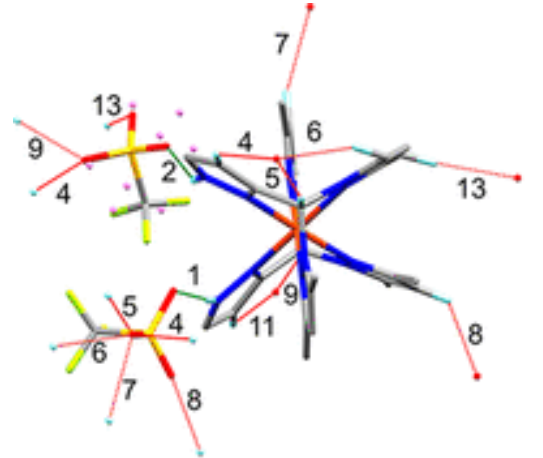

(a)

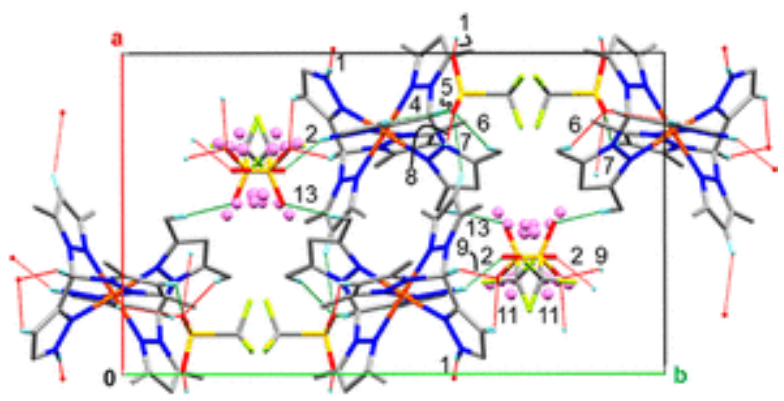

(b)

Figure 5. Noncovalent interactions of cis-1. (a) Labeling of atoms involved in interactions. Hanging and completed contacts are red and green dashed lines, respectively. Pink spheres represent a minor triflate disorder component. (b) View down the $c$-axis of the unit cell with noncovalent interactions labeled in accord with Table3.

The structure of trans-1 was determined at 250 and $100 \mathrm{~K}$; at these temperatures the crystal was light pink and violet, respectively. The crystal undergoes a reversible phase transition over this temperature range, as it is monoclinic $\left(P 2_{1} / C\right)$ at $250 \mathrm{~K}$ but triclinic $(P I)$ at $100 \mathrm{~K}$. In the $250 \mathrm{~K}$ structure, the asymmetric unit (Figure 6a) contains one well-ordered (containing S1) and one disordered triflate (containing S1a) anion in general positions and two independent $\mathrm{Fe}\left({ }^{\mathrm{H}} \mathrm{L}^{*}\right)$ units where the iron center in each is located on an inversion center thereby guaranteeing each is the trans isomer. The average Fe-N bond distance about Fe1a (Table4) of 2.18(3) $\AA$ is typical of HS iron(II) whereas that about Fe1 of 2.12(3) $\AA$ is indicative of partial LS character (HS/LS). The confused pyrazolyl $\mathrm{N}-\mathrm{H}$ groups in each serve as hydrogen-bond donors to oxygen atoms of triflate anions

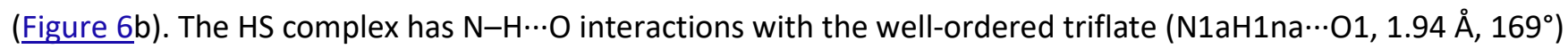

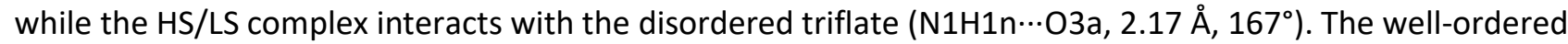

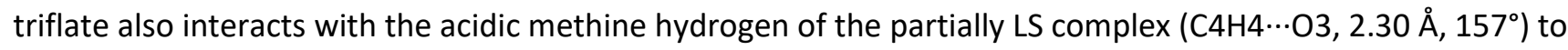
form a chain of complexes with alternating (HS/LS) Fe1 and HS Fe1a centers along the [101] direction. A more complete analysis of the supramolecular structure is given in the Supporting Information, and further discussion of the structure will continue after discussion of the $100 \mathrm{~K}$ structure. 


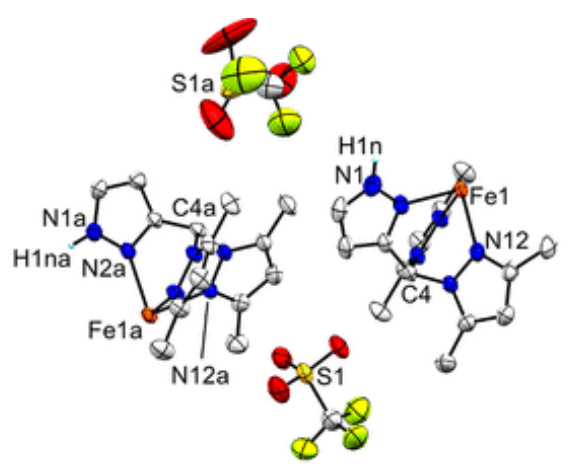

(a)

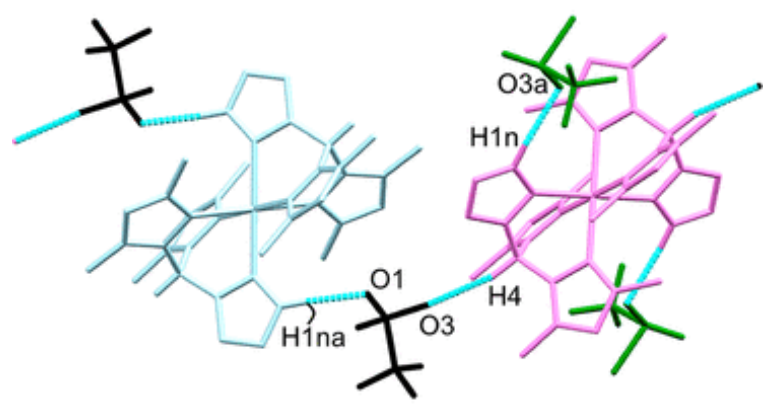

(b)

Figure 6. (a) Asymmetric unit of the $250 \mathrm{~K}$ structure of trans-[Fe $\left.\left({ }^{\mathrm{H}} \mathrm{L}^{*}\right)_{2}\right](\mathrm{OTf})_{2}$, trans-1, with partial atom labeling, and (b) view showing the shortest three hydrogen-bonding interactions ( $\sum$ van der Waals radii $-0.4 \AA$, cyan dotted lines) forming chains. Color key: black sticks = well-ordered triflate ion, green sticks = disordered triflate ion, pale blue sticks = HS dication with central Fe1a, pink sticks = partial HS/LS dication with central Fe1.

Table 4. Bond Distances (Å), Angles (deg), and Torsion Angles (deg) for trans-1

\begin{tabular}{|l|l|l|l|l|l|}
\hline $250 \mathrm{~K}$ & & & $100 \mathrm{~K}$ & & \\
\hline Bond Distances (Å) & & & & & \\
\hline Fe1-N2 & $2.082(4)$ & Fe1-N2 & $1.942(3)$ & Fe1b-N2b & $2.143(2)$ \\
\hline Fe1-N12 & $2.129(4)$ & Fe1-N12 & $2.010(2)$ & Fe1b-N12b & $2.172(3)$ \\
\hline Fe1-N22 & $2.151(4)$ & Fe1-N22 & $1.990(2)$ & Fe1b-N22b & $2.216(3)$ \\
\hline Fe1a-N2a & $2.145(4)$ & Fe1a-N2a & $2.063(3)$ & Fe1c-N2c & $2.146(3)$ \\
\hline Fe1a-N12a & $2.216(4)$ & Fe1a-N12a & $2.125(3)$ & Fe1c-N12c & $2.214(3)$ \\
\hline Fe1a-N22a & $2.173(3)$ & Fe1a-N22a & $2.139(3)$ & Fe1c-N22c & $2.179(3)$ \\
\hline Bond Angles (deg) & & & & & \\
\hline N2-Fe1-N12 & $84.52(16)$ & N2-Fe1-N12 & $87.77(10)$ & N2b-Fe1b-N12b & $83.42(10)$ \\
\hline N2-Fe1-N22 & $84.66(15)$ & N2-Fe1-N22 & $87.68(11)$ & N2b-Fe1b-N22b & $83.49(10)$ \\
\hline N12-Fe1-N22 & $85.17(14)$ & N12-Fe1-N22 & $87.28(10)$ & N12b-Fe1b-N22b & $82.84(10)$ \\
\hline N2a-Fe1-N12a & $83.82(15)$ & N2a-Fe1a-N12a & $84.98(11)$ & N2c-Fe1C-N12c & $83.49(10)$ \\
\hline N2a-Fe1-N22a & $83.60(14)$ & N2a-Fe1a-N22a & $84.57(10)$ & N2c-Fe1C-N22c & $83.37(10)$ \\
\hline N12a-Fe1-N22a & $82.79(15)$ & N12a-Fe1a-N22a & $85.62(10)$ & N12c-Fe1C-N22c & $82.04(11)$ \\
\hline Bond Torsions (deg) & & & & & \\
\hline C4C3-N2Fe1 & $-3.3(6)$ & C4C3-N2Fe1 & $0.8(4)$ & C4bC3b-N2bFe1b & $7.3(4)$ \\
\hline C4N11-N12Fe1 & $-7.7(5)$ & C4N11-N12Fe1 & $0.5(3)$ & C4bN11b-N12bFe1b & $3.9(4)$ \\
\hline C4N21-N22Fe1 & $-0.8(5)$ & C4N21-N22Fe1 & $3.9(3)$ & C4bN21b-N22bFe1b & $8.4(4)$ \\
\hline C4aC3a-N2aFe1a & $-6.7(5)$ & C4aC3a-N2aFe1a & $-8.6(4)$ & C4cC3c-N2cFe1c & $-5.8(4)$ \\
\hline C4aN11a-N12aFe1a & $-6.0(5)$ & C4aN11a-N12aFe1a & $-12.5(3)$ & C4cN11c-N12cFe1c & $-5.5(4)$ \\
\hline C4aN21a-N22aFe1a & $-3.0(5)$ & C4aN21a-N22aFe1a & $-4.5(3)$ & C4cN21c-N22cFe1c & $-3.0(4)$ \\
\hline
\end{tabular}


In the $100 \mathrm{~K}$ structure, the asymmetric unit (Figure 7a) contains three well-ordered triflate ions (containing S1, $\mathrm{S} 1 \mathrm{a}$, and S1b) and one disordered triflate (over two nearby positions in a 2:1 S1c:S1d ratio) on general positions and four independent $\mathrm{Fe}\left({ }^{\mathrm{H}} \mathrm{L}^{*}\right)$ units whose metal centers are on inversion centers generating trans isomers by symmetry. Inspection of the Fe-N distances reveals that two of the dications with Fe1b and Fe1c are HS (av Fe$\mathrm{N}=2.18(4)$ and $2.18(3) \AA$, respectively) and that the dication with a central Fe1 is $\mathrm{LS}$ (av Fe-N=1.98(3) $\AA$ ). The last dication with Fe1a has an average Fe-N distance of 2.11(4) $\AA$ that corresponds to approximately $25-33 \%$ LS character, so is labeled HS/LS. As with the $250 \mathrm{~K}$ structure, the triflate ions are hydrogen-bonded to the dications via $\mathrm{N}-\mathrm{H} \cdots \mathrm{O}$ interactions (cyan dashed lines Figure $7 \mathrm{~b}$ ). Three interactions involve well-ordered triflate ions

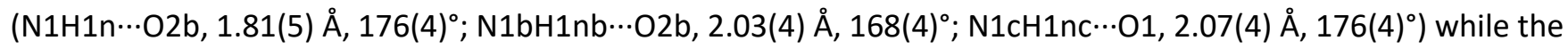
remaining interaction involves the partly LS complex and the disordered triflate (major component,

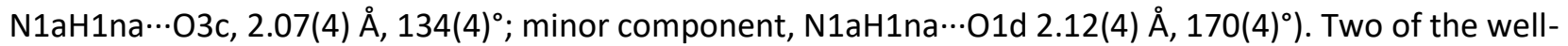

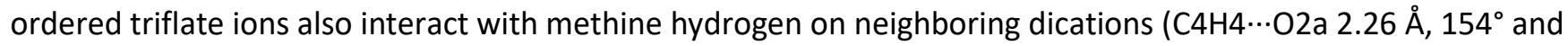
$\mathrm{C} 4 \mathrm{aH} 4 \mathrm{a} \cdots \mathrm{O} 32.21 \AA \mathrm{O}^{\circ} 154^{\circ}$ ) to form two separate chains. One chain along the [2 20 ] direction has alternating dications of HS Fe1c and (LS/HS) Fe1a while the other chain along the [1 110$]$ direction has alternating dications of HS Fe1b and (LS) Fe1. Further details of crystal packing in the $100 \mathrm{~K}$ structure are found in the Supporting Information. Figure 8 provides comparative views of the crystal packing diagrams in the $250 \mathrm{~K}$ (left) and $100 \mathrm{~K}$ (right) structures. The crystal packing is quite similar at both temperatures, with layers of HS complexes stacked alternately with layers of complexes with partially (LS/HS) or fully LS (100 K case) complexes along the $a$ direction $(250 \mathrm{~K})$ or c-direction $(100 \mathrm{~K})$, or colloquially, the SCO layer. The well-ordered triflates (black sticks, Figure 8) are found in the HS layers at each temperature. The main differences in the structures occur in the SCO layers. At $250 \mathrm{~K}$, the SCO layers contain partly HS/LS complexes (25-33\% LS character from bond distances) and disordered triflate ions. At $100 \mathrm{~K}$, one-half of the complexes in the SCO layer (25\% overall) have converted to fully LS (dark violet sticks, right of Figure 8). The other half of the complexes in this layer remain (HS/LS) (25-33\% LS character). So, on the basis of an estimation from bond distances, the entire sample is approximately $31-33 \%$ LS at $100 \mathrm{~K}$. Coincidentally, at $100 \mathrm{~K}$ one-half of the triflate ions in the SCO layer $(75 \%$ overall) are now fully ordered (red arrows bottom of Figure 8). Decreasing the temperature from 250 to $100 \mathrm{~K}$, and the associated SCO contracts the unit cell sufficiently to lock one of the triflate ions into one position. The remaining $25 \%$ of the triflate ions are disordered. If the minor disorder component (34\% occupancy) is associated with the LS component of the partial SCO, then $33.5 \%$ ( $25 \% \mathrm{LS}+34 \%$ occupancy $\times 25 \% \mathrm{HS} / \mathrm{LS}$ ) of the total complexes in the unit cell would be LS trans-1 at $100 \mathrm{~K}$. 


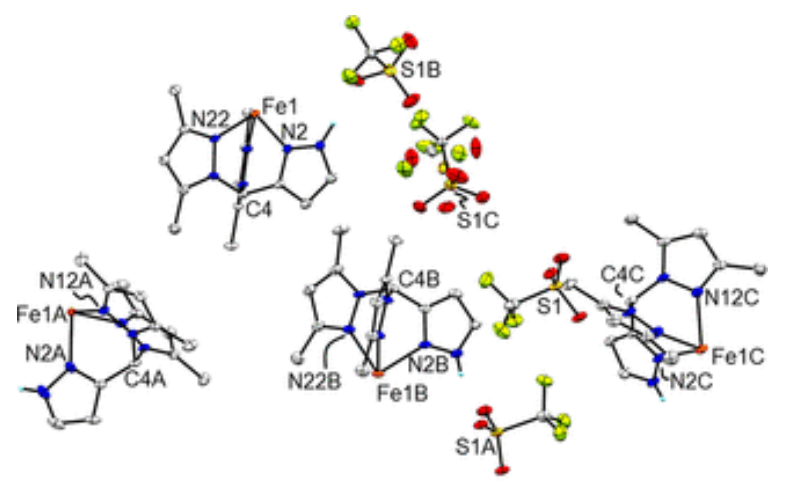

(a)

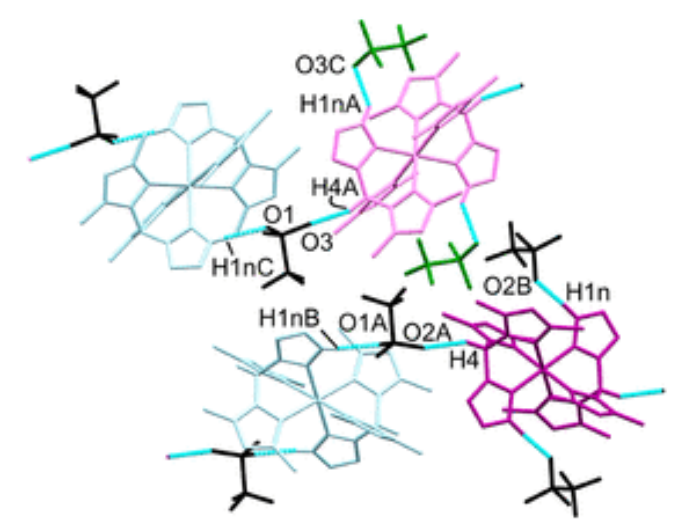

(b)

Figure 7. (a) Asymmetric unit of the $100 \mathrm{~K}$ structure of trans-[Fe $\left.\left({ }^{\mathrm{H}} \mathrm{L}^{*}\right)_{2}\right](\mathrm{OTf})_{2}$, trans-1, with partial atom labeling. (b) View showing some of the shortest hydrogen-bonding interactions ( $\Sigma$ van der Waals radii $-0.45 \AA$, cyan dotted lines) forming two chains. Color key: black sticks = well-ordered triflate ion, green sticks = disordered triflate ion, pale blue sticks $=\mathrm{HS}$ dication with central Fe1b or Fe1c, pink sticks $=$ partial HS/LS dication with central Fe1a, dark violet sticks LS dication with central Fe1.
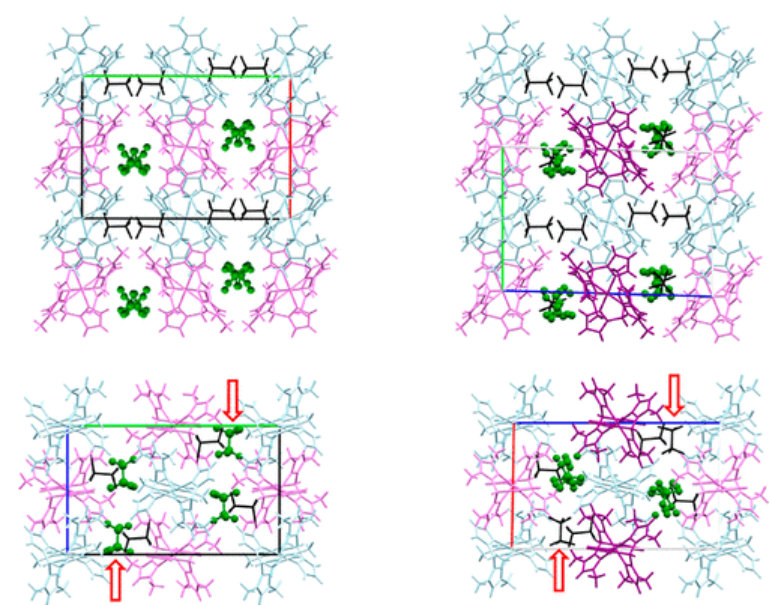

Figure 8. Comparison of a portion of the crystal packing diagrams in the $250 \mathrm{~K}$ (left) and $100 \mathrm{~K}$ (right) structures of trans-1. Top left: view down c-axis. Top right: view down $a$-axis. Bottom left: view down $a$-axis. Bottom right: view down $b$-axis. Axes color scheme: $a$-axis (red), $+b$-axis (green), and $+c$-axis (blue). Red arrows highlight transition in disorder/well-ordered triflate types upon changing temperature.

Crystals of co-1 turn violet on cooling to $77 \mathrm{~K}$, so single crystal X-ray diffraction experiments were performed at two temperatures, $250 \mathrm{~K}$ (colorless/pale blue) and $100 \mathrm{~K}$ (violet). Views of the $100 \mathrm{~K}$ structure are found 
in Figure 9 while bond distances and interatomic angles are listed in Table5. The asymmetric unit (Figure 9a) consists of one well-ordered triflate (with terminal atoms bound to the S1-C5 unit), one triflate that is disordered unequally over two nearby positions (84\% containing S1a-C5a and 16\% containing S1b-C5b), and two $\mathrm{Fe}\left({ }^{\mathrm{H}} \mathrm{L}^{*}\right)$ moieties (one with Fe1 on an inversion center and one with Fe2 on a 2-fold rotation axis). By crystallographic symmetry, the dication with Fe1 is the trans isomer (angle between iron-bound "confused" nitrogens, N2-Fe1-N2' $\left.=180.0(1)^{\circ}\right)$ whereas that with Fe2 is the cis isomer (N2-Fe2-N2' $\left.=92.5(2)^{\circ}\right)$, Figure $9 \mathrm{~b}$. At $250 \mathrm{~K}$, the average Fe-N bond distances indicate that both the trans ( $2.17 \AA$ ) and cis ( $2.16 \AA$ ) components are $\mathrm{HS} \mathrm{Fe}(\mathrm{II})$. At $100 \mathrm{~K}$, the trans isomer remains $\mathrm{HS}$ (Fe- $\mathrm{N}_{\mathrm{av}} 2.14 \AA$ ) while the cis isomer has $\mathrm{Fe}-\mathrm{N}_{\mathrm{av}}$ of 2.06(3) $\AA$, a distance between HS ( $2.18 \AA$ ) and LS (ca. $1.98 \AA$ ) roughly corresponding to about $38 \pm 12 \%$ HS character (overall $69 \% \mathrm{HS}$ or $31 \pm 6 \% \mathrm{SCO}$ ). It is noteworthy not only that the trans component has longer bond distances than the cis component but also that the ligand is more distorted with greater pyrazolyl ring twisting $\left(5.8^{\circ}\right.$ vs $4.4^{\circ}$ at $250 \mathrm{~K}$ or $4.8^{\circ}$ vs $4.5^{\circ}$ at $\left.100 \mathrm{~K}\right)$ and ring tilting $\left(171^{\circ}\right.$ vs $175^{\circ}$ at $250 \mathrm{~K}$ or $172^{\circ}$ vs $176^{\circ}$ at $\left.100 \mathrm{~K}\right)$, Figure $9 \mathrm{c}$. In other words, the cis isomer with a less distorted ligand and shorter bonds at room temperature undergoes SCO on cooling (albeit incomplete over this temperature range).

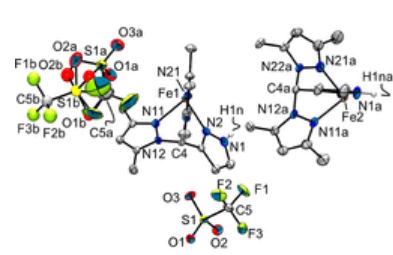

(a)

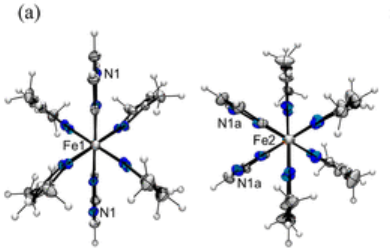

(c)

(b)

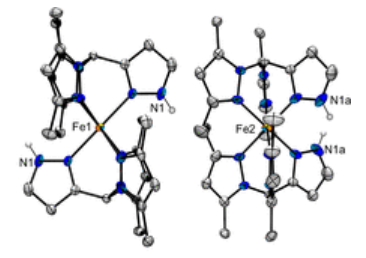

Figure 9. Views of the structure of a crystal with a $1: 1$ ratio of cis- $\mathbf{1}^{2+}:$ trans-12+, a crystal form called co-1. (a) Asymmetric unit with partial atom labeling and most hydrogen atoms removed for clarity. (b) View of the trans (left) and cis (right) dication components. (c) View of the dications down the $\mathrm{C}$ (methine)-H bond showing greater pz ring tilting in the trans isomer (left) than the cis isomer (right).

Table 5. Bond Distances ( $\AA$ ), Angles (deg), and Torsion Angles (deg) for co-1

\begin{tabular}{|l|l|l|}
\hline & $250 \mathrm{~K}$ & $100 \mathrm{~K}$ \\
\hline Bond Distances (Å) & & \\
\hline Fe1-N2 & $2.1321(19)$ & $2.103(3)$ \\
\hline Fe1-N11 & $2.2059(18)$ & $2.163(3)$ \\
\hline Fe1-N21 & $2.1850(18)$ & $2.154(3)$ \\
\hline Fe2-N2a & $2.132(2)$ & $2.032(4)$ \\
\hline Fe2-N11a & $2.178(2)$ & $2.087(3)$ \\
\hline Fe2-N21a & $2.156(2)$ & $2.064(3)$ \\
\hline Bond Angles (deg) & & \\
\hline N2-Fe1-N11 & $85.32(7)$ & $85.68(11)$ \\
\hline N2-Fe1-N21 & $84.10(7)$ & $84.82(11)$ \\
\hline N11-Fe1-N21 & $82.38(7)$ & $83.07(10)$ \\
\hline N2a-Fe2-N11a & $85.83(8)$ & $86.83(13)$ \\
\hline N2a-Fe2-N21a & $82.26(8)$ & $84.35(13)$ \\
\hline N11a-Fe2-N21a & $85.94(8)$ & $87.11(13)$ \\
\hline Bond Torsions (deg) & & \\
\hline C4C3-N2Fe1 & $-6.1(3)$ & $-6.1(4)$ \\
\hline
\end{tabular}




\begin{tabular}{|l|l|l|}
\hline C4N12-N11Fe1 & $-4.9(2)$ & $-5.0(4)$ \\
\hline C4N22-N21Fe1 & $-2.2(2)$ & $-3.2(4)$ \\
\hline C4aC3a-N2aFe2 & $-6.9(3)$ & $-5.4(4)$ \\
\hline C4aN12a-N11aFe2 & $-4.5(3)$ & $-3.8(4)$ \\
\hline C4aN22a-N21aFe2 & $5.9(3)$ & $4.4(4)$ \\
\hline
\end{tabular}

An examination of the three-dimensional supramolecular structure provides insight into why the cis component of co-1 undergoes SCO but the trans component does not. Views of the crystal packing arrangement are found in Figure 10, while Table6 lists the short noncovalent interactions that help organize the structure. The threedimensional structures of co-1 at 250 and $100 \mathrm{~K}$ are only slightly different, so the $100 \mathrm{~K}$ structure is discussed first. As stated above, there are two triflate anions, one well-ordered and one disordered. The threedimensional structure can be described by only considering charge-assisted $\mathrm{C}-\mathrm{H} \cdots \mathrm{O}$ weak hydrogen-bonding interactions $(\mathbf{7 4})$ with the well-ordered triflate where interactions with the disordered triflate further support the structure. The $\mathrm{C}-\mathrm{H} \cdots \mathrm{O}$ interactions assemble each of the cis (colored orange in Figure 10) or trans (colored black in Figure 10) isomers into separate polymeric chains (that contain only one type of isomer) that run parallel with the $c$-axis (Figure 10b,c). The cis chain is organized via a trifurcated $\mathrm{C}-\mathrm{H} \cdots \mathrm{O}$ interaction involving $\mathrm{O} 1 \mathrm{as}$ a bridging acceptor to a 5-methyl hydrogen donor $(\mathrm{H} 24 \mathrm{e})$ on one complex and both a methine $(\mathrm{H} 4 \mathrm{a})$ and a nearby 5-methyl hydrogen (H24f) donor on a neighboring complex (contacts 3, 6, and 7, Table6). The interaction of 03 of the triflate ions attached to the cis chain with the methine hydrogen of the trans isomer ( $\mathrm{H} 4$, contact 2, Table6) also places trans isomers in chains parallel to $c$ (and gives bilayer sheets parallel to the ac-plane), Figure 10b,c. The trans chains are further supported by their confused pyrazolyl hydrogens as donors $(\mathrm{H} 1 \mathrm{n}, \mathrm{H} 1)$ and oxygen atoms of disordered triflate ions (contacts 9 and 10, Table6). The $a c$-bilayer sheets are stacked along the $b$ direction by the interaction between $\mathrm{O} 2$ on one sheet and a 5-methyl hydrogen of a pz* group (H24b) on an adjacent sheet (contact 5, Table6). The other noncovalent interactions listed in Table 6 further secure this structure. This packing arrangement places the minor disorder triflate component within voids of the supramolecular framework. The minor component is still hydrogen-bonded to the trans isomer but does not bridge neighboring trans isomers within the polymer chain. Moreover, there is no hydrogen bonding to the cis isomer. It is further noted that, at $250 \mathrm{~K}$, the overall connectivity is retained but noncovalent interactions lengthen. Also, the minor triflate disorder component is not observed. Instead, there are solvent accessible voids $162 \AA^{3}$ in the same location as in the $100 \mathrm{~K}$ structure. Thus, the cis component of co-1 is more loosely packed than the trans component at both temperatures and presumably is freer to adopt an LS configuration at low temperature.

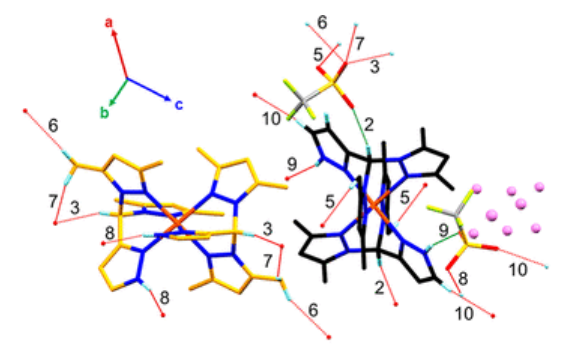

(a)

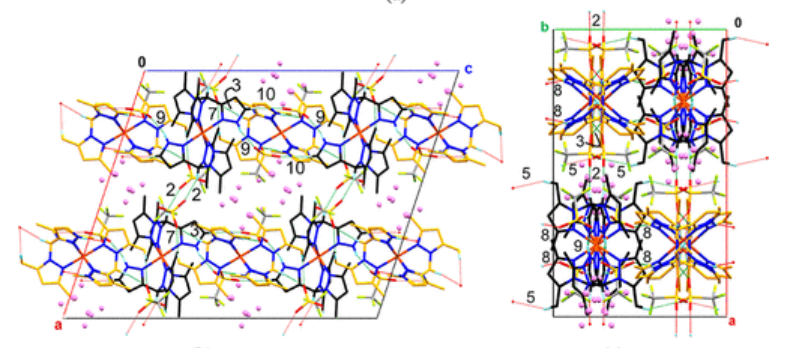

(b) 
Figure 10. Supramolecular structure of co-1. (a) View of important noncovalent interactions with atom labeling. The cis isomer has light orange carbons as capped sticks while the trans isomer shows carbon as black capped sticks. Hanging and completed contacts are red and green dashed lines, respectively. Pink spheres represent a minor triflate disorder component. (b) View of unit cell down $b$ with contact no. from Table6 labeled. (c) View of unit cell down $c$ with contacts labeled as per Table6.

Table 6. Geometries of Selected Weak Hydrogen-Bonding Interactions in co-1 at $100 \mathrm{~K}$

\begin{tabular}{|c|c|c|c|c|c|}
\hline contact & donor $(D)(-H) \cdots$ acceptor $(A)$ & $\mathrm{D}-\mathrm{H}(\AA)$ & $H \cdots A(\AA)$ & $D \cdots A(\AA)$ & $\mathrm{D}-\mathrm{H} \cdots \mathrm{A}(\mathrm{deg})$ \\
\hline \multicolumn{6}{|c|}{ Ordered Triflate } \\
\hline 1 & $\mathrm{C} 2-\mathrm{H} 2 \cdots \mathrm{O} 3$ & 0.95 & 2.60 & $3.286(5)$ & 130 \\
\hline 2 & $\mathrm{C} 4-\mathrm{H} 4 \cdots 03$ & 1.00 & 2.24 & $3.182(5)$ & 157 \\
\hline 3 & $\mathrm{C} 4 \mathrm{a}-\mathrm{H} 4 \mathrm{a} \cdots \mathrm{O}$ & 1.00 & 2.26 & $3.211(4)$ & 158 \\
\hline 4 & C14-H14a‥O3 & 0.98 & 2.57 & $3.434(5)$ & 147 \\
\hline 5 & $\mathrm{C} 24-\mathrm{H} 24 \mathrm{~b} \cdots \mathrm{O} 2$ & 0.98 & 2.46 & $3.366(5)$ & 154 \\
\hline 6 & $\mathrm{C} 24-\mathrm{H} 24 \mathrm{e} \cdots \mathrm{O}$ & 0.98 & 2.55 & $3.477(5)$ & 158 \\
\hline 7 & $\mathrm{C} 24-\mathrm{H} 24 \mathrm{f} \cdots \mathrm{O}$ & 0.98 & 2.42 & $3.279(5)$ & 145 \\
\hline \multicolumn{6}{|c|}{ Disordered Triflate } \\
\hline 8 & N1a-H1na…03a & 0.88 & 1.96 & $2.807(5)$ & 162 \\
\hline 9 & N1-H1n...01a & 0.88 & 1.93 & $2.744(5)$ & 154 \\
\hline 10 & $\mathrm{C} 1-\mathrm{H} 1 \cdots 02 \mathrm{a}$ & 0.95 & 2.45 & $3.395(6)$ & 173 \\
\hline 11 & $\mathrm{C} 1-\mathrm{H} 1 \cdots 02 \mathrm{~b}$ & 0.95 & 2.53 & $3.40(2)$ & 153 \\
\hline 12 & C1a-H1a…03b & 0.95 & 2.54 & $3.20(2)$ & 120 \\
\hline 13 & $\mathrm{C} 10 \mathrm{a}-\mathrm{H} 10 \mathrm{e} \cdots \mathrm{O} 2 \mathrm{~b}$ & 0.98 & 2.59 & $3.34(2)$ & 133 \\
\hline 14 & $\mathrm{C} 22 \mathrm{a}-\mathrm{H} 22 \mathrm{e} \cdots \mathrm{F} 1 \mathrm{~b}$ & 0.98 & 2.48 & $3.269(18)$ & 137 \\
\hline 15 & $\mathrm{C} 22 \mathrm{a}-\mathrm{H} 22 \mathrm{e} \cdots \mathrm{F} 2 \mathrm{~b}$ & 0.98 & 2.25 & $2.868(18)$ & 122 \\
\hline 16 & $\mathrm{C} 2-\mathrm{H} 2 \cdots \mathrm{F} 1 \mathrm{~b}$ & 0.95 & 2.48 & $2.977(18)$ & 113 \\
\hline
\end{tabular}

\section{Powder X-ray Diffraction}

The multiple crystal forms of 1 identified by single crystal X-ray diffraction studies prompted an investigation into the structural nature of the bulk crystalline and powder samples. First, it was found that the PXRD patterns of freshly ground bulk crystalline samples of trans-1 or co-1 matched those calculated from their single crystal Xray diffraction data. The data for ground, air-dried crystals of trans $-1 \cdot 2 \mathrm{CH}_{3} \mathrm{CN}$ mostly matched the calculated pattern but had reflections for desolvated forms, Figure 11a,b. If the initially violet trans-1.2 $\mathrm{CH}_{3} \mathrm{CN}$ is subjected to room-temperature evacuation, samples become colorless and PXRD data shows a new phase (Figure 11c,d) for trans-1. $\mathrm{CH}_{3} \mathrm{CN}$, as suggested by NMR and combustion analysis. This new phase only very slowly (several hours) converts with heating at $70^{\circ} \mathrm{C}$ under vacuum to trans-1 (Figure $11 \mathrm{e}-\mathrm{g}$ ). In contrast, samples of trans$1.4 \mathrm{CH}_{3} \mathrm{CN}$ readily lose solvent even at room temperature (neither heating nor evacuation is necessary) to give PXRD patterns identical with that of trans-1 (Figure S5). Samples of as-formed powders of $\mathbf{1}$ crystallized at room temperature by $\mathrm{Et}_{2} \mathrm{O}$ vapor diffusion had PXRD patterns that were consistent with an admixture of crystalline phases cis-1 and trans-1. It is noted that because of the similarity in unit cells at room temperature these two PXRD patterns are strikingly similar (Figure S6) but are distinguishable by peaks at $2 \theta$ (deg) = 7.3 (trans), 14.5 and 14.7 (cis) versus 14.4 and 14.8 (trans), 19.4 (cis) versus 19.6 (trans), 25.0 (cis) versus 25.2 (trans), 27.8 (trans), and 29.4 (cis). Finally, the PXRD patterns reveal that the $\mathrm{Et}_{2} \mathrm{O}$-washed, colorless, as-formed powders of $\mathbf{1}$ are mixtures trans-1, cis-1, and sometimes co-1. As described more fully in the Supporting Information, the relative composition of the mixture depends on the temperature of the reaction mixture and that at which solvent was removed under vacuum; both are controlled by solution isomerization equilibrium (vide infra) 
where high temperatures favor greater proportions of cis-1 and/or co-1 whereas room-temperature reactions and distillations gave mixtures that favored trans-1 (Figures S6 and S7).

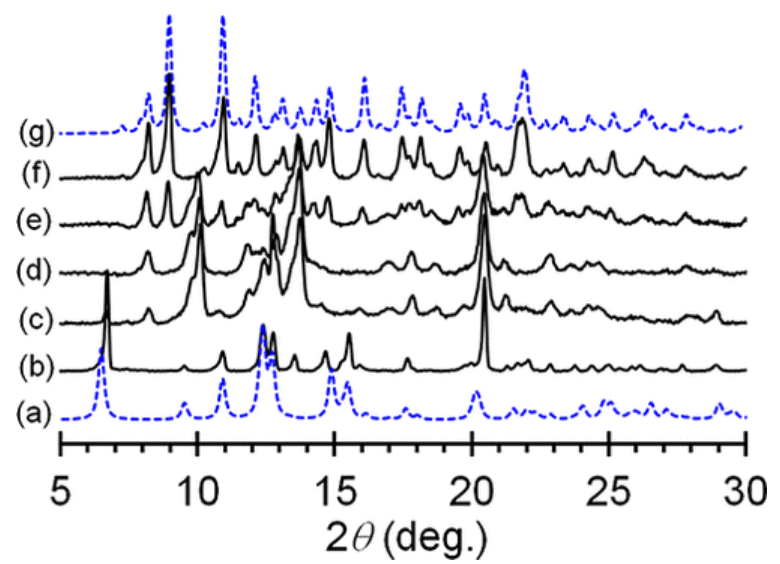

Figure 11. Calculated (blue dashed traces) and experimental (black traces) powder X-ray diffractograms (Cu Ka radiation, $295 \mathrm{~K})$ for various stages of desolvation of $\left[\mathrm{Fe}\left({ }^{\mathrm{H}} \mathrm{L}^{*}\right)_{2}\right](\mathrm{OTf})_{2} \cdot 2 \mathrm{CH}_{3} \mathrm{CN}$, trans $-1 \cdot 2 \mathrm{CH}_{3} \mathrm{CN}$. (a) Calculated pattern for trans-1.2 $2 \mathrm{CH}_{3} \mathrm{CN}$. (b) Air-dried, ground crystals of trans-1.2 $2 \mathrm{CH}_{3} \mathrm{CN}$. (c) Crystals of trans $-1 \cdot 2 \mathrm{CH}_{3} \mathrm{CN}$ dried under vacuum at $295 \mathrm{~K}$ for 5 min to give pink powder. (d) Crystals of trans $-1 \cdot 2 \mathrm{CH}_{3} \mathrm{CN}$ dried under vacuum at 295 $\mathrm{K}$ for $1 \mathrm{~h}$ to give colorless powder. (e) Crystals of trans-1.2 $2 \mathrm{CH}_{3} \mathrm{CN}$ dried under vacuum at $343 \mathrm{~K} 1 \mathrm{~h}$. (f) Crystals of trans $-1 \cdot 2 \mathrm{CH}_{3} \mathrm{CN}$ dried under vacuum at $343 \mathrm{~K}$ for $12 \mathrm{~h}$. (g) Calculated pattern of trans-1 from $250 \mathrm{~K}$ single crystal X-ray diffraction experiment.

\section{Magnetometry}

The temperature dependences of the magnetic properties of air-dried crystals of co-1, a powder sample of cis1 contaminated with minor amounts of trans-1, and phase pure powders of trans-1 and trans $-1 \cdot \mathrm{CH}_{3} \mathrm{CN}$ were investigated by SQUID magnetometry. Figure 12 gives the magnetic data, plotted as $\chi_{\mathrm{m}} T$ versus $T$. The magnetic data for co-1 (Figure 12a) shows a gradual SCO beginning near $300 \mathrm{~K}\left(\chi_{\mathrm{m}} T=3.2 \mathrm{~cm}^{3} \mathrm{~K} \mathrm{~mol}^{-1}, 100 \% \mathrm{HS}\right.$; theor $\chi_{\mathrm{m}} T=3.25 \mathrm{~cm}^{3} \mathrm{~K} \mathrm{~mol}^{-1}$ with orbital angular momentum contribution to spin-only moment) that stops after $\chi_{\mathrm{m}} T$ reaches $1.8 \mathrm{~cm}^{3} \mathrm{~K} \mathrm{~mol}^{-1}$ at $80 \mathrm{~K}(68 \% \mathrm{HS}, 32 \% \mathrm{SCO})$. This behavior is aligned with the crystallographic data that showed that only the cis component undergoes partial SCO. The $\chi_{\mathrm{m}} T$ value at $100 \mathrm{~K}$ of $2.2 \mathrm{~cm}^{3} \mathrm{~K} \mathrm{~mol}^{-}$ ${ }^{1}$ indicates $23 \%$ SCO which is on par with $31 \pm 6 \%$ SCO estimated from bond distance analysis. As shown in Figure $12 \mathrm{~b}, \chi_{\mathrm{m}} T$ in cis-1 maintains a constant value from $300 \mathrm{~K}$ to about $165 \mathrm{~K}^{\circ} 3.2 \mathrm{~cm}^{3} \mathrm{~K} \mathrm{~mol}^{-1}$ consistent with $100 \% \mathrm{HS} \mathrm{Fe}(\mathrm{II})$. Between 80 and $20 \mathrm{~K}$, the $\chi_{\mathrm{m}} T$ value drops to a constant value of $2.0 \mathrm{~cm}^{3} \mathrm{~K} \mathrm{~mol}^{-1}$, indicating about $72 \% \mathrm{HS} \mathrm{Fe}(\mathrm{II})$. Given the X-ray structural data that showed a rather long average $\mathrm{Fe}-\mathrm{N}$ bond distance of $2.11(2) \AA$ at $100 \mathrm{~K}$ (consistent with an incomplete $30 \pm 5 \%$ spin crossover) and a triflate disordered in a near 2:1 ratio over two sites, we tentatively ascribe the unusual magnetic behavior as the result of the spin crossover of the minor disorder component in cis-1; the majority of the sample remains HS. The subtle "hump" in the curve near $100 \mathrm{~K}$ is due to trans-1, as described next. For trans-1, $\chi_{\mathrm{M}} T$ at $300 \mathrm{~K}$ is $3.1 \mathrm{~cm}^{3} \mathrm{~K} \mathrm{~mol}^{-1}$ and reduces to a constant value of $2.0 \mathrm{~cm}^{3} \mathrm{~K} \mathrm{~mol}^{-1}$ upon cooling to $80 \mathrm{~K}$ or below, in accord with about $28 \% \mathrm{SCO}$ on cooling, similar to the behavior for cis-1. As opposed to the gradual transition in cis-1, that of trans-1 occurs in two unequal steps at $T_{1}=250 \mathrm{~K}(18 \% \mathrm{SCO})$ and $T_{2}=105 \mathrm{~K}(10 \% \mathrm{SCO})$ with the former being more gradual (temperature range of transition, $\Delta T, \sim 78 \mathrm{~K}$ ) than the latter $(\Delta T \sim 22 \mathrm{~K})$. The monoclinic/triclinic crystal phase transition is responsible for the abruptness of the low temperature SCO transition. In particular, the $10 \%$ SCO of this second step observed from the magnetomety data is similar to the $8.5 \%$ minor component of the disordered triflate associated with the LS component of the HS/LS iron site in the $100 \mathrm{~K}$ structure. Finally, the sample of trans $-1 \cdot \mathrm{CH}_{3} \mathrm{CN}$ of unknown structure undergoes a complete but gradual SCO with $T_{1 / 2}$ of $156 \mathrm{~K}$. 


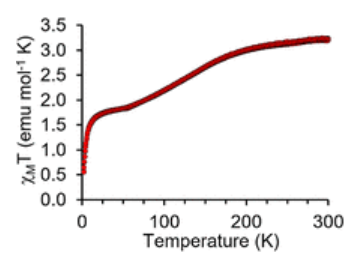

(a)

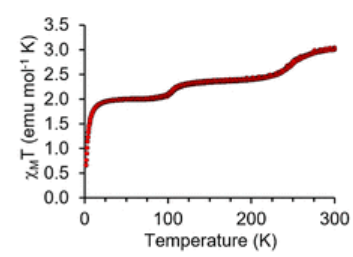

(c)

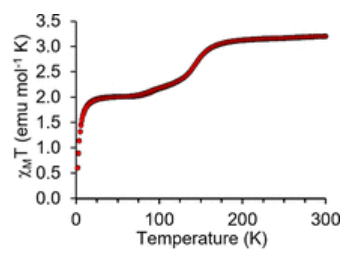

(b)

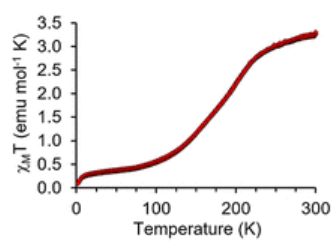

(d)

Figure 12. Magnetic susceptibility data obtained from hand-separated crystals of (a) co-1, (b) cis-1, (c) trans-1, and (d) trans-1. $\mathrm{CH}_{3} \mathrm{CN}$.

\section{Solution Properties}

The properties of the various crystalline forms in solution were investigated first by their crystallization behavior and then by ${ }^{1} \mathrm{H}$ NMR spectroscopy. First, dissolution of any of the crystalline forms followed by either evaporation or $\mathrm{Et}_{2} \mathrm{O}$ vapor diffusion over about $16 \mathrm{~h}$ (or longer) produces a mixture of crystalline forms indicating that the complexes undergo isomerization in solution. When violet crystals of trans $-1 \cdot 2 \mathrm{CH}_{3} \mathrm{CN}$ are dissolved in $\mathrm{CH}_{3} \mathrm{CN}$ at room temperature, the resulting solution is colorless and paramagnetic $\left(\mu_{\text {eff }}=5.0 \mu_{\mathrm{B}}\right)$, indicating that the LS nature of this complex is due to crystal packing effects (vide infra, DFT Calculations section). The ${ }^{1} \mathrm{H}$ NMR spectrum of $C_{2 h}$ symmetric trans-1.2 $\mathrm{CH}_{3} \mathrm{CN}$ (or of trans-1.4 $\mathrm{CH}_{3} \mathrm{CN}$ ) immediately after dissolution consists of six resonances: five for the hydrogens of the complex and one for $\mathrm{CH}_{3} \mathrm{CN}$. The resonance near $20 \mathrm{ppm}$ consists of three overlapping signals, which is evident from integration and VT NMR experiments (Figure S8). Over time, new resonances characteristic of a $C_{2}$ symmetric cis isomer (notably near 51, 48, 45, and $21 \mathrm{ppm}$, Figure 13 and Figure S9) grow in intensity at the expense of those for trans-1 until an equilibrium mixture of trans and cis isomers is reached. By monitoring the trans to cis isomerization at 22, 50, 60 , and $70^{\circ} \mathrm{C}$, full kinetic and thermodynamic parameters for the equilibrium (eq 1) were obtained (see Supporting Information for full details).

trans $-1 \rightleftarrows$ cis $-1 K=[$ cis -1$] /[$ trans -1$](1)$

(1)The trans to cis isomerization reaction (forward reaction eq 1) is first order in trans-1 with a half-life of $36.5 \mathrm{~h}$ at $295 \mathrm{~K}$ and only $19.4 \mathrm{~min}$ at $343 \mathrm{~K}$. The activation barrier for this conversion is only $83 \mathrm{~kJ} / \mathrm{mol}$, which is much smaller than typical metal-nitrogen bond dissociation enthalpies (ca. 300-400 kJ/mol).(80) Thus, the isomerization likely occurs via bond stretching and torsional modes of vibration rather than by dissociation. An observation supporting this assertion is that when solutions of 1 are spiked with excess ligand, the spectrum consists of two separate sets of resonances, one set for $\mathbf{1}$ (as a mixture of cis and trans) and one set for the ligand; the ligand exchange is slow on the time scale of the experiment. At room temperature (295 K), the isomerization proceeds until an equilibrium cis/trans ratio $\left(K_{\text {eq,295 }}\right)$ of 0.66 is achieved. At $343 \mathrm{~K}$, the equilibrium favors the cis isomer, $K_{\text {eq,343 }}=2.2$. The van't Hoff plot at four different temperatures (igure S13 ) gives $\Delta H=+22$ $\mathrm{kJ} / \mathrm{mol}$ and $\Delta S=+69 \mathrm{~J} / \mathrm{K}$ mol. The small positive value of $\Delta S$ is expected due to the lower symmetry of the cis versus trans isomer. However, the endothermic nature of the trans to cis transformation was not expected (nor was it predicted by DFT, vide infra) given the otherwise identical HS FeN 6 kernels. The enthalpic contribution must originate from discrepancies in ion pairing between each isomer, or less likely in solvation, due to the different disposition of $\mathrm{N}-\mathrm{H}$ bond donors. Perhaps the smaller electron repulsion of hydrogenbonded triflate anions in the trans versus cis isomer may be responsible for the difference in enthalpy. We will further examine this line of query in future studies that probe anion effects on SCO of this complex cation. The 
difference in the apparent composition of the as-formed powders depending on whether the solution is heated or not during evaporation (Figure S7) originates from the values of $\Delta H$ and $\Delta S$ which indicate that the cis isomer is favored above $311 \mathrm{~K}\left(38^{\circ} \mathrm{C}\right)$. In a related manner, NMR monitoring of the formation of 1 in situ by dissolving the ligand and $\mathrm{Fe}(\mathrm{OTf})_{2} \cdot 2 \mathrm{CH}_{3} \mathrm{CN}$ in $\mathrm{CD}_{3} \mathrm{CN}$ initially shows a mixture of isomers that slightly favors trans-1 but that converts rapidly to the equilibrium mixture after heating (Figures S9b and S11). The ability to isolate pure trans$1.2 \mathrm{CH}_{3} \mathrm{CN}$ from solutions of as-formed powders of 1 in $\mathrm{CH}_{3} \mathrm{CN}$ when stored in a freezer $(253 \mathrm{~K})$ is facilitated by $K_{\text {eq, } 253}=0.15$ and solubility differences in isomers. Finally, the limited boiling temperature of $\mathrm{CH}_{3} \mathrm{CN}(355 \mathrm{~K})$, the equilibrium constant at that temperature, $K_{\text {eq, } 355}=2.3$, and the larger rate constant of the reverse versus the forward reaction in eq 1 all have hampered the ability to isolate pure cis-1 in the bulk from this solvent.

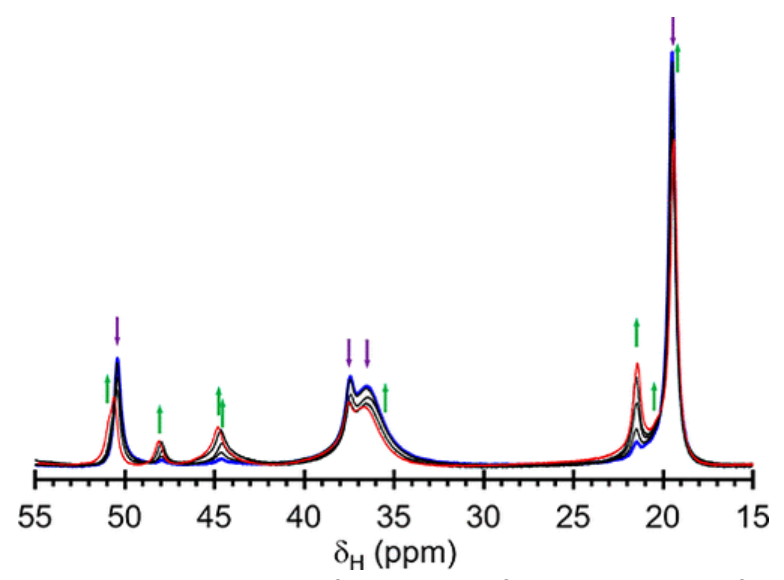

Figure 13. Overlay of the downfield portions of the $295 \mathrm{~K}^{1} \mathrm{H}$ NMR spectra of a $0.02 \mathrm{M}$ solution of trans-1.2CH $\mathrm{CN}_{3}$ in $\mathrm{CD}_{3} \mathrm{CN}$ acquired at five time points after dissolution: $5 \mathrm{~min}$ (blue), $240 \mathrm{~min}$ (black), $480 \mathrm{~min}$ (black), $1380 \mathrm{~min}$ (black), and $1800 \mathrm{~min}$ (red). The green arrows highlight emergence of resonances for the cis isomer while the purple arrows indicate the receding resonances for the trans isomer.

\section{DFT Calculations}

To gain further insight into the nature of the electronic ground state and relative stability of isomeric dications in 1, theoretical calculations were performed using a density functional method, (OPBE/def2-SV(P) $(C, H, N)$, def2QZVPP $(\mathrm{Fe}) / \mathrm{PCM}\left(\mathrm{CH}_{2} \mathrm{Cl}_{2}\right)$, that has been successfully used for other iron complexes that undergo spin crossover.(70) First, for both isomers DFT calculations predict the quintet state to be lowest in energy at $298 \mathrm{~K}$. This is in line with the experimental observation that, in solution, both isomers are paramagnetic HS species. The singlet state was higher in energy by 21 and $22 \mathrm{~kJ} / \mathrm{mol}$ for the trans and cis isomers, respectively. These small values of spin-state splitting are in the range where spin crossover is expected. Finally, the isomers are nearly degenerate, with the trans isomer being only 1-2 kJ more stable than the cis isomer in either the quintet or singlet states. This slight preference may be due to the lower interligand repulsions in the trans (two pz* methyl/pz* methyl clashes) versus the cis (three pz* methyl/pz* methyl clashes) isomer, Figure 14 . If the isomers are degenerate, then one may expect a statistical 2:1 ratio of cis:trans isomers (the value achieved in the high temperature solution NMR studies). Thus, the DFT calculations are surprisingly in rather good qualitative agreement with the experimental solution isomerization equilibrium despite not accounting for potential electrostatic interactions with anions. As mentioned above, perhaps neglecting these latter interactions in the computations is responsible for the discrepancies between calculated and experimental $\Delta H$ and $\Delta S$ values. 

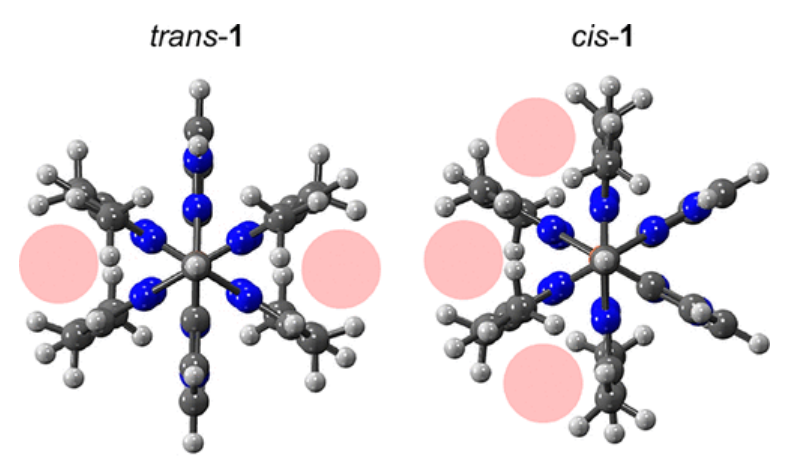

Figure 14. DFT calculated geometries of the LS form of each isomer of 1 viewed down the $\mathrm{H}-\mathrm{C}_{\text {methine }} \cdots \mathrm{Fe}$ vector, showing areas of interligand steric interactions as filled pink circles.

\section{Conclusions}

Complex 1, $\left[\mathrm{Fe}\left({ }^{\mathrm{H}} \mathrm{L}^{*}\right)_{2}\right](\mathrm{OTf})_{2}$, was initially prepared to compare electronic and magnetic properties with the parent complex $\left[\mathrm{Fe}\left({ }^{\mathrm{H}} \mathrm{L}\right)_{2}\right](\mathrm{OTf})_{2}, \mathbf{2}$ (with a $T_{1 / 2}$ near $360 \mathrm{~K}$ ). It was expected that the interligand steric interactions among methyl substituents on the pyrazolyl rings in $\mathbf{1}$ should lower $T_{1 / 2}$ (i.e., stabilize the HS state) versus the parent complex. Indeed, $\mathbf{1}$ was found to be HS in solution at room temperature in contrast to the LS complex $\mathbf{2}$. A secondary benefit of adding methyls to the normal pyrazolyl rings is that $\mathbf{1}$ enjoyed much greater solubility in $\mathrm{CH}_{3} \mathrm{CN}$ than 2 which greatly facilitated the solution NMR studies of the former. The fairly significant temperature dependence of the solution isomerization equilibrium (eq 1) observed for $\mathbf{1}$ by NMR was surprising since both the enthalpic and entropic contributions to the equilibrium were expected to be minimal on the basis of the consideration of only $\mathrm{FeN}_{6}$ cores and, perhaps, the change in point group symmetry. It would seem that interactions with the triflate anions play an important role in governing the temperature dependence. Not only does the trans isomer have fewer interligand steric interactions than the cis isomer, but also if the triflate ions here hydrogen-bonded to the acidic $\mathrm{N}-\mathrm{H}$ group in each isomer, then the triflate ions in the trans isomer would be further apart than in the cis isomer, minimizing anion-anion repulsions making the trans isomer more stable than the cis isomer. Regardless, the temperature dependence of the equilibria provided insight into conditions that would favor one isomer over another. Indeed, six different crystalline forms of 1 could be prepared: cis$1, c 0-1$, and trans-1.x $\mathrm{CH}_{3} \mathrm{CN}(x=0,1,2,4)$. It is worth comment that the rich structural chemistry, as observed for 1, was not discovered in the parent complex, $\left[\mathrm{Fe}\left({ }^{\mathrm{H}} \mathrm{L}\right)_{2}\right](\mathrm{OTf})_{2}$. Such behavior was missed due in part to the relatively high pseudosymmetry of the "confused" and "normal" pyrazolyl rings that results in crystallographically disordered dications which prevented definitive identification of isomers in the solid state and the low solubility in solution that stymied NMR characterization. It is also of interest that $\mathrm{CH}_{3} \mathrm{CN}$ solvates of cis-1 have neither been isolated nor identified by PXRD. Perhaps this is a fortuitous consequence of the solution equilibrium. It is also possible that the juxtaposition of the two $\mathrm{N}-\mathrm{H}$ groups allows for chelation of one triflate anion in solution (the other anion being either outer sphere or associated with the acidic methine) that outcompetes solvent for hydrogen bonding. In the case of the trans isomer, only monodentate coordination to the anion or solvent is possible and gives rise to the observed mixture of solvate and solvate-free forms. Regardless, five of the six crystalline forms were $\mathrm{HS}$ in the solid state at room temperature with trans $-1 \cdot 2 \mathrm{CH}_{3} \mathrm{CN}$ being the LS exception. The crystal packing of this latter derivative is remarkably efficient, being denser than co1 (and only slightly less dense than trans-1 or cis-1) despite having two solvate $\mathrm{CH}_{3} \mathrm{CN}$ molecules included in the lattice. Four of the derivatives (cis-1, co-1, and trans-1. $\times \mathrm{CH}_{3} \mathrm{CN}(x=0,1)$ showed SCO by magnetometry, and only the structure of the latter remains unknown. It is now clear after examining the average $\mathrm{pz}$ twist angles of cis$1\left(6^{\circ}\right)$, co-1 (cis component $4^{\circ}$, trans component $\left.6^{\circ}\right)$, trans $-1.4 \mathrm{CH}_{3} \mathrm{CN}\left(10^{\circ}\right)$, and $\left[\mathrm{Fe}\left({ }^{\top s} \mathrm{~L}\right)_{2}\right]\left(\mathrm{BF}_{4}\right)_{2}\left(8^{\circ}\right)$ reported earlier that the empirical " $11^{\circ}$ rule" needs to be amended, at least for $\mathrm{N}$-confused scorpionates, to state the following: If pz twisting is above $11^{\circ}$ then SCO will not be observed, but if pyrazolyl ring twisting is less than $11^{\circ}$, SCO is not guaranteed. Clearly other ligand distortions (pz-tilting $<175^{\circ}$ ) or other crystal packing effects are 
sufficient to prevent SCO of these iron(II) scorpionates. For three derivatives with known structures and that undergo SCO, the triflate anion plays an important role in their magnetic behavior. In all three cases, at least one of the triflate ions is disordered and the minor disorder component is responsible for SCO behavior. The ability for the triflate to adopt different geometries thereby giving more room for HS/LS interconversions in the dications may be promoted by the incompatibility of the $C_{3 v}$ point symmetry of the anion with 2 -fold point symmetry of the dication in most (the observed) space groups, forcing the anion to occupy crystallographic general positions (and increasing probability for disordered structures). Finally, one of the unique design features of these $\mathrm{N}$-confused $\mathrm{C}$-scorpionates is the availability of an $\mathrm{N}-\mathrm{H}$ moiety on the confused pyrazolyl ring that can be involved in hydrogen-bonding interactions with either anions or solvent. It remains unclear whether these weak hydrogen-bonding interactions have any effect on cooperativity, as both abrupt and gradual SCO transitions have been observed among the four reported examples. Future studies will be directed toward developing a better understanding of the relationships between symmetry and hydrogen-bonding capabilities of anions on the cooperativity of SCO in these systems by using judicious choices of hydrogen-bonding acceptors.

\section{Supporting Information}

The Supporting Information is available free of charge on the ACS Publications website at DOI: 10.1021 /acs.inorgchem.8b03454.

Supramolecular structure description, PXRD and NMR data, and computational details (PDF) File of models $(\underline{X Y Z})$ ic8b03454 si 002.xyz (13.54 kb) pdf ic8b03454 si 001.pdf (2.51 MB)

\section{Accession Codes}

CCDC $\underline{1883589}-1883594$ and $\underline{1917600}-1917601$ contain the supplementary crystallographic data for this paper. These data can be obtained free of charge via www.ccdc.cam.ac.uk/data request/cif, or by emailing data request@ccdc.cam.ac.uk, or by contacting The Cambridge Crystallographic Data Centre, 12 Union Road, Cambridge CB2 1EZ, UK; fax: +44 1223336033.

\section{Author Contributions}

All authors have approved the final version of this manuscript.

The authors declare no competing financial interest.

\section{Terms \& Conditions}

Electronic Supporting Information files are available without a subscription to ACS Web Editions. The American Chemical Society holds a copyright ownership interest in any copyrightable Supporting Information. Files available from the ACS website may be downloaded for personal use only. Users are not otherwise permitted to reproduce, republish, redistribute, or sell any Supporting Information from the ACS website, either in whole or in part, in either machine-readable form or any other form without permission from the American Chemical Society. For permission to reproduce, republish and redistribute this material, requesters must process their own requests via the RightsLink permission system. Information about how to use the RightsLink permission system can be found at http://pubs.acs.org/page/copyright/permissions.html.

\section{Acknowledgments}


J.R.G. thanks Dr. Gregory Morrison (University of South Carolina) for magnetic measurements and discussions.

J.R.G. also thanks Marquette University for support.

\section{References}

$\underline{1}$ Halcrow, M. A. Spin Crossover Materials, Properties and Applications; John Wiley \& Sons, Ltd., 2013.

$\underline{\mathbf{2}}$ Gutlich, P.; Goodwin, H. A. Spin Crossover in Transition Metal Compounds I-III; Topics in Current Chemistry; Springer-Verlag: Berlin, Germany, 2004; Vol. 233-235.

$\underline{3}$ Gütlich, P.; Hauser, A.; Spiering, H. Thermal and Optical Switching of Iron(II) Complexes. Angew. Chem., Int. Ed. Engl. 1994, 33, 2024- 2054, DOI: 10.1002/anie.199420241

4 Gütlich, P.; Garcia, Y.; Goodwin, H. A. Spin crossover phenomena in Fe(II) complexes. Chem. Soc. Rev. 2000, 29, 419-427, DOI: 10.1039/b003504l

$\underline{\mathbf{5}}$ Gütlich, P. Spin transition in iron(II) complexes induced by heat, pressure, light, and nuclear decay. Hyperfine Interact. 1987, 33, 105-132, DOI: 10.1007/BF02394103

$\underline{6}$ Levchenko, G. G.; Khristov, A. V.; Varyukhin, V. N. Spin crossover in iron(II)-containing complex compounds under a pressure. Low Temp. Phys. 2014, 40, 571- 585, DOI: 10.1063/1.4891445

7 Drickamer, H. G. Electronic transfer reactions in transition metal compounds at high pressure. Angew. Chem., Int. Ed. Engl. 1974, 13, 39-47, DOI: 10.1002/anie.197400391

$\underline{8}$ Renz, F. Physical and chemical induced spin crossover. J. Phys.: Conf. Ser. 2010, 217, 012022, DOI: 10.1088/1742-6596/217/1/012022

$\underline{9}$ Nègre, N.; Conséjo, C.; Goiran, M.; Bousseksou, A.; Varret, F.; Tuchagues, J. P.; Barbaste, R.; Askénazy, S.; Haasnoot, J. G. Spin transitions in a series of Fell molecular complexes induced by a strong-pulsed magnetic field. Physica B 2001, 91, 294-91, DOI: 10.1016/S0921-4526(00)00616-5

10 Unruh, D.; Homenya, P.; Kumar, M.; Sindelar, R.; Garcia, Y.; Renz, F. Spin state switching of metal complexes by visible light or hard X-rays. Dalton Trans. 2016, 45, 14008-14018, DOI: 10.1039/C6DT01745B

11 Létard, J.-F. Photomagnetism of iron(II) spin crossover complexes-the T(LIESST) approach. J. Mater. Chem. 2006, 16, 2550-2559, DOI: 10.1039/B603473J

12 Lefter, C.; Tan, R.; Dugay, J.; Tricard, S.; Molnár, G.; Salmon, L.; Carrey, J.; Nicolazzi, W.; Rotaru, A.; Bousseksou, A. Unidirectional electric field-induced spin-state switching in spin crossover based microelectronic devices. Chem. Phys. Lett. 2016, 644, 138-141, DOI: 10.1016/j.cplett.2015.11.036

13 Kumar, K. S.; Ruben, M. Emerging trends in spin crossover (SCO) based functional materials and devices. Coord. Chem. Rev. 2017, 346, 176- 205, DOI: 10.1016/j.ccr.2017.03.024

$\underline{14}$ Lefter, C.; Davesne, V.; Salmon, L.; Molnar, G.; Demont, P.; Rotaru, A.; Bousseksou, A. Charge transport and electrical properties of spin crossover materials: towards nanoelectronic and spintronic devices. Magnetochemistry 2016, 2, 18, DOI: 10.3390/magnetochemistry2010018

15 Holovchenko, A.; Dugay, J.; Gimenez-Marques, M.; Torres-Cavanillas, R.; Coronado, E.; van der Zant, H. S. J. Near room-temperature memory devices based on hybrid spin crossover@ $\mathrm{SiO}_{2}$ nanoparticles coupled to single-layer graphene nanoelectrodes. Adv. Mater. 2016, 28, 7228- 7233, DOI: 10.1002/adma.201600890

16 Manrique-Juarez, M. D.; Mathieu, F.; Shalabaeva, V.; Cacheux, J.; Rat, S.; Nicu, L.; Leichle, T.; Salmon, L.; Molnar, G.; Bousseksou, A. A Bistable Microelectromechanical System Actuated by Spin crossover Molecules. Angew. Chem., Int. Ed. 2017, 56, 8074- 8078, DOI: 10.1002/anie.201702739

17 von Ranke, P. J. A microscopic refrigeration process triggered through spin crossover mechanism. Appl. Phys. Lett. 2017, 110, 181909, DOI: 10.1063/1.4982792

18 Kucheriv, O. I.; Oliynyk, V. V.; Zagorodnii, V. V.; Launets, V. L.; Gural'skiy, I. A. Spin crossover Materials towards Microwave Radiation Switches. Sci. Rep. 2016, 6, 38334, DOI: 10.1038/srep38334 
19 Thorarinsdottir, A. E.; Gaudette, A. I.; Harris, T. D. Spin crossover and high-spin iron(ii) complexes as chemical shift ${ }^{19} \mathrm{~F}$ magnetic resonance thermometers. Chem. Sci. 2017, 8, 2448- 2456, DOI: 10.1039/C6SC04287B

20 Jeon, I.-R.; Park, J. G.; Haney, C. R.; Harris, T. D. Spin crossover iron(II) complexes as PARACEST MRI thermometers. Chem. Sci. 2014, 5, 2461- 2465, DOI: 10.1039/C4SC00396A

21 Brooker, S. Spin crossover with thermal hysteresis: practicalities and lessons learnt. Chem. Soc. Rev. 2015, 44, 2880-2892, DOI: 10.1039/C4CS00376D

$\underline{22}$ Polymorphs:

(a) Shatruk, M.; Phan, H.; Chrisostomo, B. A.; Suleimenova, A. Symmetry-Breaking Structural Phase Transitions in Spin crossover Complexes. Coord. Chem. Rev. 2015, 289-290, 62-73, DOI: 10.1016/j.ccr.2014.09.018 .

(b) Tao, J.; Wei, R.-J.; Huang, R.-B.; Zheng, L.-S. Polymorphism in Spin crossover Systems. Chem. Soc. Rev. 2012, 41, 703- 737, DOI: 10.1039/C1CS15136C

23 (a) Vela, S.; Paulsen, H. Deciphering Crystal Packing Effects in the Spin Crossover of six [Fe(2pic) ${ }_{3} \mathrm{Cl}_{2}$ Solvatomorphs. Dalton Trans 2019, 48, 1237-1245, DOI: 10.1039/C8DT04394A .

(b) Bartual-Murgui, C.; Codina, C.; Roubeau, O.; Aromí, G. A Sequential Method to Prepare Polymorphs and Solvatomorphs of $\left[\mathrm{Fe}(1,3-\mathrm{bpp})_{2}\right]\left(\mathrm{ClO}_{4}\right)_{2} \cdot \mathrm{nH}_{2} \mathrm{O}(\mathrm{n}=0,1,2)$ with Varying Spin-Crossover Behaviour. Chem. Eur. J. 2016, 22, 12767-12777, DOI: 10.1002/chem.201601843

$\underline{24}$ (a) Berdiell, I. C.; Kulmaczewski, R.; Cespedes, O.; Halcrow, M. A. An Incomplete Spin Transition Associated with a Z' $=1$ to Z'=24 Crystallographic Symmetry Breaking. Chem. Eur. J. 2018, 24, 5055- 5059, DOI: 10.1002/chem.201704896.

(b) Craig, G. A.; Roubeau, O.; Aromi, G. Spin state switching in 2,6-bis(pyrazol-3-yl)pyridine (3-bpp) based Fe(II) complexes. Coord. Chem. Rev. 2014, 269, 13-31, DOI: 10.1016/j.ccr.2014.02.002

$\underline{\mathbf{2 5}}$ Roubeau, O. Triazole-Based One-Dimensional Spin crossover Coordination Polymers. Chem. - Eur. J. 2012, 18, 15230-15244, DOI: 10.1002/chem.201201647

$\underline{\mathbf{2 6}}$ Olguin, J.; Brooker, S. Spin crossover active iron(II) complexes of selected pyrazole-pyridine/pyrazine ligands. Coord. Chem. Rev. 2011, 255, 203-240, DOI: 10.1016/j.ccr.2010.08.002

27 Munoz, M. C.; Real, J. A. Thermo-, piezo-, photo- and chemo-switchable spin crossover iron(II)metallocyanate based coordination polymers. Coord. Chem. Rev. 2011, 255, 2068-2093, DOI: 10.1016/j.ccr.2011.02.004

28 Goodwin, H. A. Spin crossover in iron(II) tris(diimine) and bis(terimine) systems. Top. Curr. Chem. 2004, 233, 59- 90, DOI: 10.1007/b13529

29 Phan, H.; Hrudka, J. J.; Igimbayeva, D.; Lawson Daku, L. M.; Shatruk, M. A Simple Approach for Predicting the Spin State of Homoleptic Fe(II) Tris-diimine Complexes. J. Am. Chem. Soc. 2017, 139, 6437-6447, DOI: 10.1021/jacs.7b02098

30 Trofimenko, S. Scorpionates: The Coordination Chemistry of Polypyrazolylborate Ligands; Imperial Press: London, 1999.

31 Pettinari, C. Scorpionates II: Chelating Borate Ligands; Imperial Press: London, 2008.

$\underline{\mathbf{3 2}}$ Long, G. J.; Grandjean, F.; Reger, D. L. Spin Crossover in Pyrazolylborate and Pyrazolylmethane Complexes. Top. Curr. Chem. 2004, 233, 91-122, DOI: 10.1007/b13530

33 Lavrenova, L. G.; Shakirova, O. G. Spin Crossover and Thermochromism of Iron(II) Coordination Compounds with 1,2,4-Triazoles and Tris(pyrazol-1-yl)methanes. Eur. J. Inorg. Chem. 2013, 2013, 670- 682, DOI: 10.1002/ejic.201200980

34 Real, J. A.; Muñoz, M. C.; Faus, J.; Solans, X. Spin Crossover in Novel Dihydrobis(1-pyrazolyl)borate $\left[\mathrm{H}_{2} \mathrm{~B}(\mathrm{pz})_{2}\right]-$ Containing Iron(II) Complexes. Synthesis, X-ray Structure, and Magnetic Properties of $\left[\mathrm{FeL}\left\{\mathrm{H}_{2} \mathrm{~B}(\mathrm{pz})_{2}\right\}_{2}\right](\mathrm{L}$ = 1,10-Phenanthroline and 2,2'-Bipyridine). Inorg. Chem. 1997, 36, 3008-3013, DOI: 10.1021/ic960965c

$\underline{35}$ (a) Moliner, N.; Salmon, L.; Capes, L.; Muñoz, M. C.; Létard, J.-F.; Bousseksou, A.; Tuchagues, J.-P.; McGarvey, J. J.; Dennis, A. C.; Castro, M.; Burriel, R.; Real, J. A. Thermal and Optical Switching of Molecular Spin 
States in the $\left\{\left[\mathrm{FeL}\left[\mathrm{H}_{2} \mathrm{~B}(\mathrm{pz})_{2}\right]_{2}\right\}\right.$ Spin crossover System ( $\mathrm{L}=$ bpy, phen). J. Phys. Chem.

B 2002, 106, 4276- 4283, DOI: 10.1021/jp013872b .

(b) Galet, A.; Gaspar, A. B.; Agusti, G.; Muñoz, M. C.; Levchenko, G.; Real, J. A. Pressure Effect Investigations on the Spin Crossover Systems $\left\{\mathrm{Fe}\left[\mathrm{H}_{2} \mathrm{~B}(\mathrm{pz})_{2}\right]_{2}(\right.$ bipy $\left.)\right\}$ and $\left\{\mathrm{Fe}\left[\mathrm{H}_{2} \mathrm{~B}(\mathrm{pz})_{2}\right]_{2}(\mathrm{phen})\right\}$. Eur. J. Inorg.

Chem. 2006, 2006, 3571-3573, DOI: 10.1002/ejic.200600517

36 Xue, S.; Guo, Y.; Rotaru, A.; Müller-Bunz, H.; Morgan, G. G.; Trzop, E.; Collet, E.; Oláh, J.; Garcia, Y. Spin Crossover Behavior in a Homologous Series of Iron(II) Complexes based on Functionalized Bipyridyl Ligands. Inorg. Chem. 2018, 57, 9880- 9891, DOI: 10.1021/acs.inorgchem.8b00850

37 Moertel, M.; Witt, A.; Heinemann, F. W.; Bochmann, S.; Bachmann, J.; Khusniyarov, M. M. Synthesis, Characterization, and Properties of Iron(II) Spin- Crossover Molecular Photoswitches Functioning at Room Temperature. Inorg. Chem. 2017, 56, 13174-13186, DOI: 10.1021/acs.inorgchem.7b01952

$\underline{\mathbf{3 8}}$ Ru, J.; Yu, F.; Shi, P.-P.; Jiao, C.-Q.; Li, C.-H.; Xiong, R.-G.; Liu, T.; Kurmoo, M.; Zuo, J.-L. Three Properties in One Coordination Complex: Chirality, Spin Crossover, and Dielectric Switching. Eur. J. Inorg.

Chem. 2017, 2017, 3144- 3149, DOI: 10.1002/ejic.201700609

39 Luo, Y.-H.; Nihei, M.; Wen, G.-J.; Sun, B.-W.; Oshio, H. Ambient-Temperature Spin-State Switching Achieved by Protonation of the Amino Group in $\left[\mathrm{Fe}\left(\mathrm{H}_{2} \mathrm{Bpz}_{2}\right)_{2}\left(\right.\right.$ bipy- $\left.\left.\mathrm{NH}_{2}\right)\right]$. Inorg. Chem. 2016, 55, 8147-8152, DOI: 10.1021/acs.inorgchem.6b01193

$\underline{40}$ Mahfoud, T.; Molnár, G.; Cobo, S.; Salmon, L.; Thibault, C.; Vieu, C.; Demont, P.; Bousseksou, A. Electrical properties and non-volatile memory effect of the $\left[\mathrm{Fe}\left(\mathrm{HB}(\mathrm{pz})_{3}\right)_{2}\right]$ spin crossover complex integrated in a microelectrode device. Appl. Phys. Lett. 2011, 99, 053307, DOI: 10.1063/1.3616147

$\underline{41}$ Davesne, V.; Gruber, M.; Studniarek, M.; Doh, W. H.; Zafeiratos, S.; Joly, L.; Sirotti, F.; Silly, M. G.; Gaspar, A. B.; Real, J. A.; Schmerber, G.; Bowen, M.; Weber, W.; Boukari, S.; Da Costa, V.; Arabski, J.; Wulfhekel, W.; Beaurepaire, E. Hysteresis and change of transition temperature in thin films of $\mathrm{Fe}\left\{\left[\mathrm{Me}{ }_{2} \mathrm{Pyrz}\right]_{3} \mathrm{BH}\right\}_{2}$, a new sublimable spin crossover molecule. J. Chem. Phys. 2015, 142, 194702, DOI: 10.1063/1.4921309

$\underline{42}$ lasco, O.; Boillot, M.-L.; Bellec, A.; Guillot, R.; Rivière, E.; Mazerat, S.; Nowak, S.; Morineau, D.; Brosseau, A.; Miserque, F.; Repain, V.; Mallah, T. The disentangling of hysteretic spin transition, polymorphism and metastability in bistable thin films formed by sublimation of bis(scorpionate) Fe(II) molecules. J. Mater. Chem. C 2017, 5, 11067- 11075, DOI: 10.1039/C7TC03276E

43 Ossinger, S.; Naggert, H.; Kipgen, L.; Jasper-Toennies, T.; Rai, A.; Rudnik, J.; Nickel, F.; Arruda, L. M.; Bernien, M.; Kuch, W.; Berndt, R.; Tuczek, F. Vacuum-Evaporable Spin crossover Complexes in Direct Contact with a Solid Surface: Bismuth versus Gold. J. Phys. Chem. C 2017, 121, 1210-1219, DOI: 10.1021/acs.jpcc.6b10888

$\underline{44}$ Beniwal, S.; Zhang, X.; Mu, S.; Naim, A.; Rosa, P.; Chastanet, G.; Letard, J.-F.; Liu, J.; Sterbinsky, G. E.; Arena, D. A.; Dowben, P. A.; Enders, A. Surface-induced spin state locking of the $\left[\mathrm{Fe}\left(\mathrm{H}_{2} \mathrm{~B}(\mathrm{pz})_{2}\right)_{2}(\right.$ bipy $\left.)\right]$ spin crossover complex. J. Phys. (Paris) 2016, 28, 206002, DOI: 10.1088/0953-8984/28/20/206002

45 Naggert, H.; Rudnik, J.; Kipgen, L.; Bernien, M.; Nickel, F.; Arruda, L. M.; Kuch, W.; Naether, C.; Tuczek, F. Vacuum-evaporable spin crossover complexes: physicochemical properties in the crystalline bulk and in thin films deposited from the gas phase. J. Mater. Chem. C 2015, 3, 7870-7877, DOI: 10.1039/C5TC00930H

$\underline{46}$ Bernien, M.; Naggert, H.; Arruda, L. M.; Kipgen, L.; Nickel, F.; Miguel, J.; Hermanns, C. F.; Krüger, A.; Krüger, D.; Schierle, E.; Weschke, E.; Tuczek, F.; Kuch, W. Highly Efficient Thermal and Light-Induced Spin-State Switching of an Fe(II) Complex in Direct Contact with a Solid Surface. ACS Nano 2015, 9, 8960-8966, DOI: 10.1021/acsnano.5b02840

47 Milek, M.; Heinemann, F. W.; Khusniyarov, M. M. Spin Crossover Meets Diarylethenes: Efficient Photoswitching of Magnetic Properties in Solution at Room Temperature. Inorg.

Chem. 2013, 52, 11585-11592, DOI: 10.1021/ic401960x 
48 Goodman, M. A.; Nazarenko, A. Y.; Casavant, B. J.; Li, Z.; Brennessel, W. W.; DeMarco, M. J.; Long, G.; Goodman, M. S. Tris(5-methylpyrazolyl)methane: Synthesis and Properties of Its Iron(II) Complex. Inorg. Chem. 2012, 51, 1084- 1093, DOI: 10.1021/ic2022038

49 Goodman, M. A.; DeMarco, M. J.; Tarasek, S. E.; Nazarenko, A. Y.; Brennessel, W.; Goodman, M. S. Iron complexes of tris(pyrazolyl)ethane ligands methylated in the 3-, 4-, and 5-positions. Inorg. Chim. Acta 2014, 423, 358-368, DOI: 10.1016/j.ica.2014.08.046

50 Sohrin, Y.; Kokusen, H.; Matsui, M. Control of Ligand Field Strength through Intra- and Interligand Contact. Octahedral Iron(II) Poly(pyrazolyl)borate Complexes. Inorg. Chem. 1995, 34, 3928-3934, DOI: 10.1021/ic00119a014

$\underline{51}$ Hamon, P.; Thépot, J.-Y.; Le Floch, M.; Boulon, M.-E.; Cador, O.; Golhen, S.; Ouahab, L.; Fadel, L.; Saillard, J.Y.; Hamon, J.-R. Dramatic Remote Substituent Effects on the Electronic Spin State of Bis(scorpionate) Iron(II) Complexes. Angew. Chem., Int. Ed. 2008, 47, 8687- 8691, DOI: 10.1002/anie.200802567

$\underline{52}$ Reger, D. L.; Gardinier, J. R.; Elgin, J. D.; Smith, M. D.; Hautot, D.; Long, G. J.; Grandjean, F. Structure-Function Correlations in Iron(II) Tris(pyrazolyl)borate Spin-State Crossover Complexes. Inorg. Chem. 2006, 45, 8862-8875, DOI: 10.1021/ic0607437

53 Gardinier, J. R.; Meise, K. J.; Jahan, F.; Lindeman, S. V. Reaction Chemistry of Silver(I) Trifluoromethanesulfonate Complexes of Nitrogen-Confused C-Scorpionates. Inorg. Chem. 2018, 57, 1572-1589, DOI: 10.1021/acs.inorgchem.7b02927

54 Gardinier, J. R.; Treleven, A. R.; Meise, K. J.; Lindeman, S. V. Accessing Spin crossover Behaviour in Iron(II) complexes of N-Confused Scorpionate Ligands. Dalton Trans. 2016, 45, 12639-12643, DOI: 10.1039/C6DT01898J

$\underline{55}$ (a) Reger, D. L.; Little, C. A.; Rheingold, A. L.; Lam, M.; Concolino, T.; Mohan, A.; Long, G. J. Structural, Electronic, and Magnetic Properties of $\left\{\mathrm{Fe}\left[\mathrm{HC}\left(3,5-\mathrm{Me}_{2} \mathrm{pz}\right)_{3}\right]_{2}\right\}\left(\mathrm{BF}_{4}\right)_{2}(\mathrm{pz}=$ Pyrazolyl): Observation of Unusual Spin crossover Behavior. Inorg. Chem. 2000, 39, 4674-4675, DOI: 10.1021/ic000721z .

(b) Reger, D. L.; Little, C. A.; Young, V. G., Jr.; Pink, M. Variable-Temperature X-ray Structural Investigation of $\left\{\mathrm{Fe}\left[\mathrm{HC}\left(3,5-\mathrm{Me}_{2} \mathrm{pz}\right)_{3}\right]_{2}\right\}\left(\mathrm{BF}_{4}\right)_{2}$ (pz = Pyrazolyl Ring): Observation of a Thermally Induced Spin State Change from All High Spin to an Equal High Spin-Low Spin Mixture, Concomitant with the Onset of Nonmerohedral Twinning. Inorg. Chem. 2001, 40, 2870- 2874, DOI: 10.1021/ic010056+ .

(c) Reger, D. L.; Little, C. A.; Smith, M. D.; Long, G. J. Solid-State Structural and Magnetic Investigations of $\left\{\mathrm{M}\left[\mathrm{HC}\left(3,5-\mathrm{Me}_{2} \mathrm{pz}\right)_{3}\right]_{2}\right\}\left(\mathrm{BF}_{4}\right)_{2}(\mathrm{M}=\mathrm{Fe}, \mathrm{Co}, \mathrm{Ni}, \mathrm{Cu})$ : Observation of a Thermally Induced Solid-State Phase Change Controlling an Iron(II) Spin-State Crossover. Inorg. Chem. 2002, 41, 4453-4460, DOI: 10.1021/ic0112645

$\underline{56}$ Reger, D. L.; Little, C. A.; Rheingold, A. L.; Lam, M.; Liable-Sands, L. M.; Rhagitan, B.; Concolino, T.; Mohan, A.; Long, G. J.; Briois, V.; Grandjean, F. A Synthetic, Structural, Magnetic, and Spectral Study of Several $\left.\{\text { Fe[tris(pyrazolyl)methane }]_{2}\right\}\left(\mathrm{BF}_{4}\right)_{2}$ Complexes: Observation of an Unusual Spin-State Crossover. Inorg. Chem. 2001, 40, 1508-1520, DOI: 10.1021/ic001102t.

Briois, V.; Sainctavit, P.; Long, G. J.; Grandjean, F. Importance of Photoelectron Multiple Scattering in the Iron KEdge X-ray Absorption Spectra of Spin crossover Complexes: Full Multiple Scattering Calculations for Several Iron(II) Trispyrazolylborate and Trispyrazolylmethane Complexes. Inorg.

Chem. 2001, 40, 912- 918, DOI: 10.1021/ic0007153

$\underline{57}$ Reger, D. L.; Elgin, J. D.; Foley, E. A.; Smith, M. D.; Grandjean, F.; Long, G. J. Structural, Magnetic, and Mössbauer Spectral Study of the Electronic Spin-State Transition in [Fe\{HC(3-Mepz) 2 (5Mepz) $\left.\}_{2}\right]\left(\mathrm{BF}_{4}\right)_{2}$. Inorg. Chem. 2009, 48, 9393-9401, DOI: 10.1021/ic901259e

58 Moubaraki, B.; Leita, B. A.; Halder, G. J.; Batten, S. R.; Jensen, P.; Smith, J. P.; Cashion, J. D.; Kepert, C. J.; Létard, J.-F.; Murray, K. S. Structure, magnetism and photomagnetism of mixed-ligand tris(pyrazolyl)methane iron(II) spin crossover compounds. Dalton Trans 2007, 4413-4426, DOI: 10.1039/b708773j 
$\underline{59}$ (a) Moertel, M.; Witt, A.; Heinemann, F. W.; Bochmann, S.; Bachmann, J.; Khusniyarov, M. M. Synthesis, Characterization, and Properties of Iron(II) Spin crossover Molecular Photoswitches Functioning at Room Temperature. Inorg. Chem. 2017, 56, 13174-13186, DOI: 10.1021/acs.inorgchem.7b01952 .

(b) Rösner, B.; Milek, M.; Witt, A.; Gobaut, B.; Torelli, P.; Fink, R. H.; Khusniyarov, M. M. Reversible Photoswitching of a Spin crossover Molecular Complex in the Solid Stateat Room Temperature. Angew. Chem., Int. Ed. 2015, 54, 12976-12980, DOI: 10.1002/anie.201504192

60 Fulmer, G. R.; Miller, A. J. M.; Sherden, N. H.; Gottlieb, H. E.; Nudelman, A.; Stoltz, B. M.; Bercaw, J. E.; Goldberg, K. I. NMR Chemical Shifts of Trace Impurities: Common Laboratory Solvents, Organics, and Gases in Deuterated Solvents Relevant to the Organometallic Chemist. Organometallics 2010, 29, 2176- 2179, DOI: 10.1021/om100106e

$\underline{\mathbf{6 1}}$ (a) Evans, D. F. The determination of the paramagnetic susceptibility of substances in solution by nuclear magnetic resonance. J. Chem. Soc. 1959, 2003- 2005, DOI: 10.1039/jr9590002003 .

(b) Evans, D. F.; Fazakerley, G. V.; Phillips, R. F. Organometallic compounds of bivalent europium, ytterbium, and samarium. J. Chem. Soc. A 1971, 1931-1934, DOI: 10.1039/j19710001931.

(c) Piguet, C. Paramagnetic Susceptibility by NMR: The "Solvent Correction" Removed for Large Paramagnetic Molecules. J. Chem. Educ. 1997, 74, 815-816, DOI: 10.1021/ed074p815

62 Morrison, G.; zur Loye, H.-C. Simple correction for the sample shape and radial offset effects on SQUID magnetometers: Magnetic measurements on $\mathrm{Ln}_{2} \mathrm{O}_{3}(\mathrm{Ln}=\mathrm{Gd}$, Dy, Er) standards. J. Solid State Chem. 2015, 221, 334-337, DOI: 10.1016/j.jssc.2014.10.026

63 Bain, G. A.; Berry, J. F. Diamagnetic Corrections and Pascal's Constants. J. Chem. Educ. 2008, 85, 532- 536, DOI: 10.1021/ed085p532

64 Agilent Technologies. CrysAlisProVersion 1.171.34.46 (release 25-11-2010 CrysAlis171.NET); (compiled Nov 25 2010, 17:55:46).

65 Dolomanov, O. V.; Bourhis, L. J.; Gildea, R. J.; Howard, J. A. K.; Puschmann, H. OLEX2: a complete structure solution, refinement and analysis program. J. Appl. Crystallogr. 2009, 42, 339-341, DOI: $10.1107 /$ S0021889808042726

66 Sheldrick, G. M. SHELXTL, Version 6.12; Bruker Analytical X-ray Systems, Inc.: Madison, WI, 2001.

67 (a) Swart, M.; Groenhof, A. R.; Ehlers, A. W.; Lammertsma, K. Validation of Exchange-Correlation Functionals for Spin States of Iron Complexes. J. Phys. Chem. A 2004, 108, 5479- 5483, DOI: 10.1021/jp049043i .

(b) Swart, M.; Ehlers, A. W.; Lammertsma, K. Performance of the OPBE exchange-correlation functional. Mol. Phys. 2004, 102, 2467- 2474, DOI: 10.1080/0026897042000275017

68 Weigend, F.; Ahlrichs, R. Balanced basis sets of split valence, triple zeta valence and quadruple zeta valence quality for $\mathrm{H}$ to Rn: Design and assessment of accuracy. Phys. Chem. Chem.

Phys. 2005, 7, 3297-3305, DOI: 10.1039/b508541a

$\underline{69}$ (a) Liddle, B. J.; Wanniarachchi, S.; Hewage, J. S.; Lindeman, S. V.; Bennett, B.; Gardinier, J. R. Electronic Communication Across Diamagnetic Metal Bridges: A Homoleptic Gallium(III) Complex of a Redox-Active Diarylamido-Based Ligand and Its Oxidized Derivatives. Inorg. Chem. 2012, 51, 12720-12728, DOI: 10.1021/ic301437f .

(b) Wanniarachchi, S.; Liddle, B. J.; Kizer, B.; Hewage, J. S.; Lindeman, S. V.; Gardinier, J. R. Syntheses and Electronic Properties of Rhodium(III) Complexes Bearing a Redox-Active Ligand. Inorg. Chem. 2012, 51, 10572- 10580, DOI: 10.1021/ic300772h .

(c) Wanniarachchi, S.; Liddle, B. J.; Toussaint, J.; Lindeman, S. V.; Bennett, B.; Gardinier, J. R. Using sterics to promote reactivity in $\mathrm{fac}_{-} \mathrm{Re}(\mathrm{CO})_{3}$ complexes of some 'non-innocent' NNN-pincer ligands. Dalton Trans. 2011, 40, 8776-8787, DOI: 10.1039/c1dt10030k

$\underline{70}$ (a) Güell, M.; Solà, M.; Swart, M. Spin-state splittings of iron(II) complexes with trispyrazolyl ligands. Polyhedron 2010, 29, 84-93, DOI: 10.1016/j.poly.2009.06.006 . 
(b) Gruden-Pavlović, M.; Stepanović, S.; Perić, M.; Güell, M.; Swart, M. A density functional study of the spin state energetics of polypyrazolylborato complexes of first-row transition metals. Phys. Chem. Chem. Phys. 2014, 16, 14514- 14522, DOI: 10.1039/c3cp55488k .

(c) Swart, M.; Gruden, M. Spinning Around in Transition-Metal Chemistry. Acc. Chem. Res. 2016, 49, 2690-2697, DOI: 10.1021/acs.accounts.6b00271 .

(d) Sirirak, J.; Sertphon, D.; Phonsri, W.; Harding, P.; Harding, D. J. Comparison of density functionals for the study of the high spin low spin gap in Fe(III) spin crossover complexes. Int. J. Quantum Chem. 2017, 117, e25362 DOI: 10.1002/qua.25362

71 Scalmani, G.; Frisch, M. J. Continuous surface charge polarizable continuum models of solvation. I. General formalism. J. Chem. Phys. 2010, 132, 114110-114124, DOI: 10.1063/1.3359469

$\underline{72}$ Frisch, M. J.; Trucks, G. W.; Schlegel, H. B.; Scuseria, G. E.; Robb, M. A.; Cheeseman, J. R.; Scalmani, G.; Barone, V.; Petersson, G. A.; Nakatsuji, H.; Li, X.; Caricato, M.; Marenich, A. V.; Bloino, J.; Janesko, B. G.; Gomperts, R.; Mennucci, B.; Hratchian, H. P.; Ortiz, J. V.; Izmaylov, A. F.; Sonnenberg, J. L.; WilliamsYoung, D.; Ding, F.; Lipparini, F.; Egidi, F.; Goings, J.; Peng, B.; Petrone, A.; Henderson, T.; Ranasinghe, D.; Zakrzewski, V. G.; Gao, J.; Rega, N.; Zheng, G.; Liang, W.; Hada, M.; Ehara, M.; Toyota, K.; Fukuda, R.; Hasegawa, J.; Ishida, M.; Nakajima, T.; Honda, Y.; Kitao, O.; Nakai, H.; Vreven, T.; Throssell, K.; Montgomery, J. A., Jr.; Peralta, J. E.; Ogliaro, F.; Bearpark, M. J.; Heyd, J. J.; Brothers, E. N.; Kudin, K. N.; Staroverov, V. N.; Keith, T. A.; Kobayashi, R.; Normand, J.; Raghavachari, K.; Rendell, A. P.; Burant, J. C.; Iyengar, S. S.; Tomasi, J.; Cossi, M.; Millam, J. M.; Klene, M.; Adamo, C.; Cammi, R.; Ochterski, J. W.; Martin, R. L.; Morokuma, K.; Farkas, O.; Foresman, J. B.; Fox, D. J. Gaussian 16, Revision B.01; Gaussian, Inc.: Wallingford, CT, 2016.

$\underline{73}$ (a) Arunan, E.; Desiraju, G. R.; Klein, R. A.; Sadlej, J.; Scheiner, S.; Alkorta, I.; Clary, D. C.; Crabtree, R. H.; Dannenberg, J. J.; Hobza, P.; Kjaergaard, H. G.; Legon, A. C.; Mennucci, B.; Nesbitt, D. J. Defining the hydrogen bond: An account (IUPAC Technical Report). Pure Appl. Chem. 2011, 83, 1619-1636, DOI: 10.1351/PAC-REP-10-01-01.

(b) Arunan, E.; Desiraju, G. R.; Klein, R. A.; Sadlej, J.; Scheiner, S.; Alkorta, I.; Clary, D. C.; Crabtree, R. H.; Dannenberg, J. J.; Hobza, P.; Kjaergaard, H. G.; Legon, A. C.; Mennucci, B.; Nesbitt, D. J. Definition of the hydrogen bond (IUPAC Recommendations 2011). Pure Appl. Chem. 2011, 83, 1637- 1641, DOI: 10.1351/PAC-REC-10-01-02 .

(c) Desiraju, G. R.; Steiner, T. The Weak Hydrogen Bonding in Structural Chemistry and Biology; Oxford University Press: New York, 1999.

(d) Taylor, R.; Kennard, O. Hydrogen Bond Geometry in Organic Crystals. Acc. Chem. Res. 1984, 17, 320-326, DOI: 10.1021/ar00105a004

$\underline{74}$ (a) Bernstein, J. It Isn't. Cryst. Growth Des. 2013, 13, 961-964, DOI: 10.1021/cg301519k .

(b) Gu, Y.; Kar, T.; Scheiner, S. Fundamental Properties of the $\mathrm{CH} \cdots \mathrm{O}$ Interaction: Is It a True Hydrogen Bond?. J. Am. Chem. Soc. 1999, 121, 9411-9422, DOI: 10.1021/ja991795g .

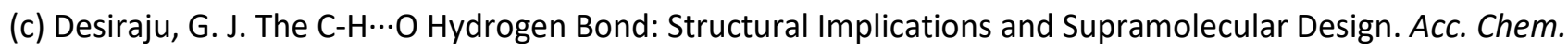
Res. 1996, 29, 441-449, DOI: 10.1021/ar950135n .

(d) Steiner, T.; Saenger, F. J. Am. Chem. Soc. 1992, 114, 10146-10154, DOI: 10.1021/ja00052a009 .

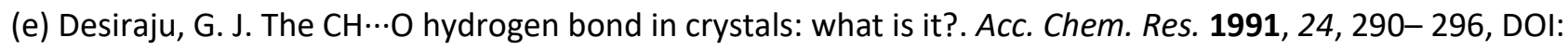
10.1021/ar00010a002 .

(f) Taylor, R.; Kennard, O. Crystallographic evidence for the existence of $\mathrm{CH} \cdots \mathrm{O}, \mathrm{CH} \cdots \mathrm{N}$ and $\mathrm{CH} \cdots \mathrm{Cl}$ hydrogen bonds. J. Am. Chem. Soc. 1982, 104, 5063- 5070, DOI: 10.1021/ja00383a012 .

(g) Gardinier, J. R.; Tatlock, H. M.; Hewage, J. S.; Lindeman, S. V. Cyclic versus Polymeric Supramolecular Architectures in Metal Complexes of Dinucleating Ligands: Silver(I) Trifluoromethanesulfonate Complexes of the Isomers of Bis(di(1H-pyrazolyl)methyl)-1,1'-biphenyl. Cryst. Growth Des. 2013, 13, 3864-3877, DOI: 10.1021/cg400466k 
$\underline{75}$ (a) Takahashi, H.; Tsuboyama, S.; Umezawa, Y.; Honda, K.; Nishio, M. CH/ $\pi$ Interactions as Demonstrated in the Crystal Structure of Host/Guest Compounds. A Database Study. Tetrahedron 2000, 56, 6185-6191, DOI: 10.1016/S0040-4020(00)00575-5 .

(b) Tsuzuki, S.; Honda, K.; Uchimaru, T.; Mikami, M.; Tanabe, K. Origin of the Attraction and Directionality of the $\mathrm{NH} / \pi$ Interaction: Comparison with $\mathrm{OH} / \pi$ and $\mathrm{CH} / \pi$ Interactions. J. Am. Chem. Soc. 2000, 122, 11450-11458, DOI: 10.1021/ja001901a .

(c) Nishio, M.; Hirota, M.; Umezawa, Y. The CH-T Interaction: Evidence, Nature, and Consequences; Wiley-VCH, Inc.: New York, 1998.

(d) Umezawa, Y.; Tsuboyama, S.; Honda, K.; Uzawa, J.; Nishio, M. CH/ $\pi$ Interaction in the Crystal Structure of Organic Compounds. A Database Study. Bull. Chem. Soc. Jpn. 1998, 71, 1207-1213, DOI: 10.1246/bcsj.71.1207 .

(e) Braga, D.; Grepioni, F.; Tedesco, E. X-H--- $\pi(X=\mathrm{O}, \mathrm{N}, \mathrm{C})$ Hydrogen Bonds in Organometallic Crystals. Organometallics 1998, 17, 2669-2672, DOI: 10.1021/om971096h

$\underline{76}$ (a) Choudhury, A. R.; Row, T. N. G. Cryst. Growth Des. 2004, 4, 47- 52, DOI: 10.1021/cg034137n .

(b) van den Berg, J. A.; Seddon, K. R. Critical Evaluation of C-H...X Hydrogen Bonding in the Crystalline State. Cryst. Growth Des. 2003, 3, 643-661, DOI: 10.1021/cg034083h.

(c) Brammer, L.; Bruton, E. A.; Sherwood, P. Fluoride ligands exhibit marked departures from the hydrogen bond acceptor behavior of their heavier halogen congeners. New J. Chem. 1999, 23, 965-968, DOI: 10.1039/a906512a .

(d) Grepioni, F.; Cojazzi, G.; Draper, S. M.; Scully, N.; Braga, D. Crystal Forms of Hexafluorophosphate Organometallic Salts and the Importance of Charge-Assisted C-H $\cdots \mathrm{F}$ Hydrogen Bonds. Organometallics 1998, 17, 296-307, DOI: 10.1021/om9706626.

(e) Thalladi, V. R.; Weiss, H.-C.; Bläser, D.; Boese, R.; Nangia, A.; Desiraju, G. R. C-H ‥F Interactions in the Crystal Structures of Some Fluorobenzenes. J. Am. Chem. Soc. 1998, 120, 8702-8710, DOI: 10.1021/ja981198e

77 Coronado, E.; Giménez-López, M. C.; Giménez-Saiz, C.; Romero, F. M. Spin crossover complexes as building units of hydrogen-bonded nanoporous Structures. Cryst. Eng. Comm 2009, 11, 2198-2203, DOI: 10.1039/b911137a

$\underline{78}$ Roberts, T. D.; Little, M. A.; Tuna, F.; Kilner, C. A.; Halcrow, M. A. Isostructural salts of the same complex showing contrasting thermal spin-crossover mediated by multiple phase changes. Chem. Commun. 2013, 49, 6280-6282, DOI: 10.1039/c3cc43613f

79 Bartual-Murgui, C.; Codina, C.; Roubeau, O.; Aromí, G. A Sequential Method to Prepare Polymorphs and Solvatomorphs of $\left[\mathrm{Fe}(1,3-\mathrm{bpp})_{2}\right]\left(\mathrm{ClO}_{4}\right)_{2} \cdot \mathrm{nH}_{2} \mathrm{O}(\mathrm{n}=0,1,2)$ with Varying Spin-Crossover Behaviour. Chem. Eur. J. 2016, 22, 12767-12776, DOI: 10.1002/chem.201601843

80 CRC Handbook of Chemistry and Physics, 77th ed.; Lide, D. R., Ed.; CRC Press: Boca Raton, FL, 1996; Section 9, Table 1. 